\title{
Affiliation of Dihydrolipoyl Dehydrogenase Allozymes in Mycorrhizae of European Forest Trees and Characterization of the Enzyme of the Matt Bolete (Xerocomus pruinatus) and the Bay Bolete ( $X$. badius)
}

\author{
Uwe Schirkonyer, Gunter M. Rothe \\ Johannes Gutenberg-University, Mainz, Germany \\ Email: uwe@schirkonyer.de
}

How to cite this paper: Schirkonyer, U. and Rothe, G.M. (2018) Affiliation of Dihydrolipoyl Dehydrogenase Allozymes in Mycorrhizae of European Forest Trees and Characterization of the Enzyme of the Matt Bolete (Xerocomus pruinatus) and the Bay Bolete ( $X$. badius). Open Journal of Ecology, 8, 356-377.

https://doi.org/10.4236/oje.2018.86022

Received: April 25, 2018

Accepted: June 12, 2018

Published: June 15, 2018

Copyright $(9) 2018$ by authors and Scientific Research Publishing Inc. This work is licensed under the Creative Commons Attribution International License (CC BY 4.0).

http://creativecommons.org/licenses/by/4.0/

\begin{abstract}
Mycorrhizal roots of the deciduous trees European beech (Fagus sylvatica (L.)) and Sessile oak (Quercus petraea (MattuschkaLiebl.)) and the conifers Norway spruce (Picea abies (L.) H. Karst.) and European larch (Larix decidua (Mill.)) associated with the ectomycorrhizal fungi matt bolete (Xerocomus pruinatus (Fries 1835)) or bay bolete ( $X$. badius (Fries 1818)) were analysed with respect to the occurrence of dihydrolipoyl dehydrogenase (EC 1.8.1.4) allozymes. In root tissues of the two deciduous trees, two gene loci could be visualized after cellulose acetate electrophoresis while three loci were expressed in root tissues of the two coniferous species. The two fungal species and further ectomycorrhizal fungi expressed exclusively one dihydrolipoyl dehydrogenase gene. In Xerocomus pruinatus and X. badius, the dihydrolipoyl dehydrogenase gene consists of $1460 \mathrm{bp}$ and $1370 \mathrm{bp}$, respectively, including five introns each consisting of $52 \mathrm{bp}$. Their DNA sequences correspond to 70 to $90 \%$ to other fungal dihydrolipoyl dehydrogenase genes. One monomer of the dimeric dihydrolipoyl dehydrogenase enzyme consists of 486 (X. pruinatus) or 454 (X. badius) amino acids which sum up to a molecular mass of $55 \mathrm{kDa}$ (X. pruinatus), respectively $52 \mathrm{kDa}$ (X. badius). The number of positively charged amino acid residues makes 79 (X. pruinatus) and 68 ( $X$. badius) and the number of negatively charged amino acid residues was calculated to make 46 ( $X$. pruinatus) and 48 ( $X$. badius); isoelectric points make 9.99 (X. pruinatus) and 9.68 (X. badius). Calculated three dimensional structures reveal a short NADH binding site being part of a larger FAD-binding site and a binding/dimerization domain.
\end{abstract}




\section{Keywords}

Amino Acid Sequence, cDNA, Ectomycorrhizae, Fagus sylvatica, Gene Sequence, Larix decidua, mRNA, Dihydrolipoyl Dehydrogenase, Picea abies, Quercus petraea, Xerocomus pruinatus, Xerocomus badius

\section{Introduction}

Most European forest trees form at their root tips, a symbiosis with ectomycorrhizal fungi belonging to the ascomycota, basidiomycota or mitosporic fungi [1] [2]. The hyphae of ectomycorrhizal fungi associated with the root tips of their host trees inhibit the formation of long roots and cause instead the development of coralloid branched short roots [3] [4] [5]. The fungal hyphae partly grow between cells of the outer mantle of the root tips, forming a Hartig net, but also extend into the soil. This way they are able to mediate between the soil and their hosts supplying the trees with nutrients and water while obtaining organic nutrients from their hosts, especially carbohydrates. The difficulty is that in forest soils plant nutrients occur mostly in an organic form which cannot be taken up by ectomycorrhizal fungi [6]. That is why they excrete various enzymes to hydrolyze the corresponding components. Proteases serve to hydrolyze proteins [7], peroxidases split humus acids, and chitins are hydrolyzed by chitinases [8]. Phosphoric acid is set free from organic soil compounds either by excreted phosphomono- and diesterases hydrolyzing e.g. inositol phosphate, sugar phosphates and polyphosphates [8] [9] or by excreting organic acids such as oxalic acid or by excretion of protons [10]. Mycorrhizal roots are predominantly found within the upper soil horizon which indicates that they gain energy by use of oxygen processed in mitochondria to obtain energy in form of ATP. Mitochondria take up pyruvate, some amino acids and several fatty acids from the cytoplasm and transfer these metabolites to the citrate cycle where they are used to provide the basis for several molecular syntheses and to gain energy (GTP) and reduction equivalents $\left(\mathrm{NADH}+\mathrm{H}^{+}, \mathrm{FADH}_{2}\right)$. The latter are transmitted to the respiration chain where they are oxidized $\left(\mathrm{NAD}^{+}, \mathrm{FAD}\right)$ and the arising electrons are transferred to oxygen while the protons set free are used for the generation of an electrochemical gradient providing the energy to synthesize ATP via the membrane bound enzyme ATP synthase [11]. The enzyme dihydrolipoyl dehydrogenase (EC 1.8.1.4) is part of two enzyme complexes of the citric acid cycle namely pyruvate dehydrogenase (EC 1.2.4.1) and a-ketoglutarate dehydrogenase (EC 1.2.4.2). After electrophoretic separations of native mycorrhizal extracts varying dihydrolipoyl dehydrogenase isozyme patterns result. In this study we investigated mycorrhizal roots of several European forest trees in order to allocate the various dihydrolipoyl dehydrogenase enzymes to the root tissues and the hyphae of the mycorrhizal fungi matte bolete (Xerocomus pruinatus) and bay bolete ( $X$. badius). The fungal enzyme was studied in more detail de- 
termining its DNA and cDNA sequence, amino acid sequence, molecular weight, isoelectric point and the putative secondary structure. The data and results presented here were collected during my doctoral thesis in the Department of Biology at the Johannes Gutenberg-University (Mainz, Germany).

\section{Materials and Methods}

\subsection{Stand Characteristics}

Mycorrhizal samples and fruiting bodies were collected from European beech (Fagus sylvatica (L.)), Sessile oak (Quercus petraea (MattuschkaLiebl.)), Norway spruce (Picea abies (L.) H. Karst.) and European larch (Larix decidua (Mill.)) growing in pure stands at the south-side of the Taunus Mountains situated on the southern part of the state of Hesse, Germany (Table 1). Samples were taken in April and June and in September and October $50 \mathrm{~cm}$ to $1 \mathrm{~m}$ away from a trunk at a soil depth of $5 \mathrm{~cm}$. Fruiting bodies were collected in autumn. The exact sampling periods are given in Table 1 .

The collected mycorrhizae were put in marked plastic bags and transported at $4^{\circ} \mathrm{C}$ in a cooled box to the lab where they were put in ice water and cleaned from adhering soil and humus particles under a microscope. Then, mycorrhizae of the same species were put in $1.5 \mathrm{ml}$ Safelock Eppendorf tubes and stored at $-20^{\circ} \mathrm{C}$.

\subsection{Mycorrhizae with Xerocomus Species}

The matt bolete (Xerocomus pruinatus (Fr. \& Hoek)) and the bay bolete (X. badius) belonging to the Basidiomycetes are forming mycorrhizae with fine roots of conifers and deciduous trees [2] [12]. Their fruiting bodies are found all over Germany [13]. Mycorrhizae with Xerocomus pruinatus are silvery-white to light yellow. They are morphologically similar to X. badius (Fr.: Fr.) Kuhn.: Gilbert, $X$. chrysenteron (Bull.) Quil., X. subtomentosus (L.: Fr.) Quil. andBoletus edulis Bull.: Fr. [4] [5]. Therefore, $X$. pruinatus and $X$. badius were identified by ITS-RFLP-analyses using the endonuclease Hinf I [14] [15]. To approve the results of ITS analyses selected samples were used to sequence the ITS region.

\subsection{Fruiting Bodies of the Two Xerocomus Species}

The cap of the fruiting body of $X$. pruinatus can reach a diameter of $10 \mathrm{~cm}$. Its

Table 1. Location of the investigated forest stands in the Taunus Mountains.

\begin{tabular}{|c|c|c|c|c|}
\hline Forest district & \multicolumn{3}{|c|}{ Wiesbaden-Chausseehaus } & Königstein \\
\hline Near the city of & \multicolumn{2}{|c|}{ Taunusstein } & Glashütten & Königstein \\
\hline \multirow{2}{*}{ GPS } & $\mathrm{N} 50^{\circ} 07.875^{\prime}$ & $\mathrm{N} 50^{\circ} 07.875^{\prime}$ & $\mathrm{N} 50^{\circ} 13.508^{\prime}$ & $\mathrm{N} 50^{\circ} 12.623^{\prime}$ \\
\hline & 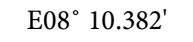 & E08 ${ }^{\circ} 10.705^{\prime}$ & $\mathrm{E}^{\circ} 8^{\circ} 24.018^{\prime}$ & E08 ${ }^{\circ} 25.992^{\prime}$ \\
\hline Tree species & $\begin{array}{c}\text { Norway spruce } \\
\text { (Picea abies) }\end{array}$ & $\begin{array}{l}\text { European beech } \\
\text { (Fagus sylvatica) }\end{array}$ & $\begin{array}{c}\text { Sessile oak } \\
\text { (Quercus petraea) }\end{array}$ & $\begin{array}{l}\text { European larch } \\
\text { (Larix decidua) }\end{array}$ \\
\hline Sampling period & $\begin{array}{l}\text { Apr-June/ } \\
\text { Sept-Nov } \\
2006-2010\end{array}$ & $\begin{array}{l}\text { Apr-June/ } \\
\text { Sept-Nov } \\
2006-2010\end{array}$ & $\begin{array}{l}\text { Sep-Oct } 2009 \\
\text { June-July } 2010\end{array}$ & $\begin{array}{c}\text { Sept. - Nov. } 2005 \\
\text { June } 2010\end{array}$ \\
\hline
\end{tabular}


shape is at first hemispherical, later convex to flattened. Its colour varies from light brown to greyish or dark brown to sometimes olivaceous or reddish brown to almost black. The cap is dry, velvety or finely dusted. The stipe is cylindrical to almost club-shaped, sometimes hardly swollen in its lower part. The yellow stipe downwards gradually gets a reddish colour. Stipe and pale yellow flesh and tubes are bluing when bruised or injured. The diameter and the shape of the cap of the fruiting body of $X$. badius are similar to that of $X$. pruinatus. The colour of the cap of $X$. badius varies from dark reddish brown to chestnut brown to dark brick. The cap is smooth when dry, but distinctly viscid under wet weather. The stipe of the fruiting body is cylindrical, spindle-shaped or almost club-shaped and often tapered towards the base. Tubes and flesh of X. badius are whitish or yellowish and turn blue when injured (cf.

http://boletales.com/genera/xerocomus/x-pruinatus/).

\subsection{Protein Extraction}

Native proteins were extracted from mycorrhizal roots associated with $X$. pruinatus or $X$. badius, non mycorrhizal fine roots of seedlings, mycorrhizal roots separated into root tissues and enclosing hyphae, and fruiting bodies. Mycorrhizae were separated into hyphae and central root-tissues under an enlargement of $25 \times$ fixing a mycorrhizal root put in ice water with a fine tweezers and separating the outer hyphae with a needle or a preparation forceps [4]. A $1.5 \mathrm{ml}$ Eppendorf tube was weighted, filled with a mycorrhizal sample and weighted again to determine the amount of fresh weight filled in. Then the sample was homogenized with a micropistill in fluid nitrogen. After homogenization the proteins were extracted on ice. To $100 \mathrm{mg}$ of frozen and pulverized mycorrhiza $200 \mu \mathrm{l} \mathrm{ex}-$ traction medium and $7.5 \mathrm{mg}$ PVPP (polyvinylpyrrolidone) were added. The extraction medium contained: $30 \mathrm{mg}(2.5 \mathrm{mM})$ cysteine, $3.3 \mathrm{mg}(0.2 \mathrm{mM})$ mercaptobenzothiazole, $95 \mathrm{mg}(5 \mathrm{mM})$ Na-metabisulfite, $186 \mathrm{mg}(5 \mathrm{mM})$ $\mathrm{Na}_{2}$-EDTA, $102 \mathrm{mg}(5 \mathrm{mM}) \mathrm{MgCl}_{2} \times 6 \mathrm{H}_{2} \mathrm{O}, 39.2 \mathrm{mg}(0.5 \mathrm{M}) \mathrm{NADP}, 33.2 \mathrm{mg}$ $(0.5 \mathrm{M}) \mathrm{NAD}, 14 \mathrm{~g}(14 \% \mathrm{w} / \mathrm{v})$ sucrose, $0.5 \mathrm{~g}(0.5 \% \mathrm{w} / \mathrm{v}) \mathrm{BSA}$ and $0.5 \mathrm{~g}(0.5 \%$ w/v) TWEEN ${ }^{\circledR} 80$ in $100 \mathrm{ml}$ of $0.1 \mathrm{M}$ sodium phosphate buffer of $\mathrm{pH} 7.0$ (57.7 $\mathrm{ml}$ of $1 \mathrm{M}$ di-sodiumhydrogenphosphate and $42.3 \mathrm{ml}$ of $1 \mathrm{M}$ sodiumdihydrogen-phosphate [16]. Then, the mixture was centrifuged at $4^{\circ} \mathrm{C}$ for $30 \mathrm{~min}$ at 5000 $\times \mathrm{g}$. The supernatant containing the native proteins was aliquoted, snap-frozen until further use, and then frozen at $-20^{\circ} \mathrm{C}$, or directly used in cellulose acetate electrophoretic separations.

\subsection{Cellulose Acetate Electrophoresis}

Cellulose acetate gels (Titan III, $7.6 \mathrm{~cm} \times 7.6 \mathrm{~cm}$, Helena Laboratories, Beaumont, Texas) were swollen under about $8^{\circ} \mathrm{C}$ for $20 \mathrm{~min}$ in electrophoresis buffer which consisted of: $0.05 \mathrm{M}$ Tris, $0.001 \mathrm{M} \mathrm{Na}_{2}$-EDTA, $0.001 \mathrm{M} \mathrm{MgCl}_{2}$ and $0.18 \mathrm{M}$ maleic acid, pH 7.8 (modified according to [17]). Then the two chambers of the electrophoretic device were filled with buffer and two filter paper bridges $(7 \mathrm{~cm}$ 
long and $12 \mathrm{~cm}$ wide) were installed to connect the cellulose acetate gel with its gel side for $3 \mathrm{~mm}$ at each end. Then the gel was submitted for $5 \mathrm{~min}$ to a pre-electrophoresis at $200 \mathrm{~V}$. After that the gel was taken off and $0.25 \mu \mathrm{l}$ samples applied by use of a Super-Z-12 application kit (Helena Laboratories). Usually sample applications were repeated three times to gain enough enzyme activity. Then the gel side of the cellulose acetate gel was again put on the platform of the electrophoresis chamber, contacted to the buffer strips, and submitted to $200 \mathrm{~V}$ for $30 \mathrm{~min}[18]$.

\subsection{Visualization of Dihydrolipoyl Dehydrogenase Allozymes}

Immediately after electrophoresis dihydrolipoyl dehydrogenase activities were visualized covering gels with an agar overlay. The staining solution consisted of $1 \mathrm{ml} \mathrm{0.1} \mathrm{M} \mathrm{Tris-HCl} \mathrm{buffer,} \mathrm{pH} 8.5,1.5 \mathrm{ml} \mathrm{NADH}$ solution $(3 \mathrm{mg} / \mathrm{ml}), 5$ drops DCIP (2,6-dichlorphenol-indophenol solution, $3 \mathrm{mg} / \mathrm{ml}$ ) and 5 drops MTT (3-(4,5-dimethyl-2-thiazolyl)-2,5-diphenyl-2H-tetrazoliumbromid solution, 10 $\mathrm{mg} / \mathrm{ml}$ ) [19] [20]. To that mixture $2 \mathrm{ml}$ of a boiling agar solution (40 $\mathrm{mg}$ agar agar in $2 \mathrm{ml}$ distilled water) were added, mixed and poured on the dry-tipped gel. After the agar had set, the covered cellulose acetate gels were incubated in the dark at room temperature until enzyme bands were visible. Then the overlay was washed under running tape water and afterwards put into a shaking water bath up to several hours. If the staining solution is intensively coloured and enzyme activity is low, the staining solution must be washed from the gel for several hours until the weak enzyme bands are clearly visible. In the case of light staining solutions and high enzyme activity the colour bands can be seen after a few minutes.

The decolorized gels were photographed and put on a transmitted light plate to note the visible enzyme bands. Gels were then dried over night between several layers of dry tissue and then stored in welded polyethylene pockets.

\subsection{DNA Extraction}

Total DNA was extracted according to [14] with a modified CTAB (cetyltrimethyl ammonium bromide-protocol [21] as published recently [15].

\subsection{PCR-RFLP Analysis}

To identify mycorrhizal samples and fruiting bodies, the multicopy internal transcribed spacer (ITS) region of their ribosomal DNA (rDNA) was amplified and sequenced. The rDNA repeats, comprising the $18 \mathrm{~S}$ rRNA gene, the ITS-1-spacer, the 5.8S rRNA, the ITS-2-spacer and the 28S rRNA gene, was amplified using the primer pair ITS1 [22] and ITS4b [23] (Table 2). Primer ITS1 binds to the 3 '-end of the $18 \mathrm{~S}$ rRNA gene and primer ITS4b binds to the 5 '-end of the $28 \mathrm{~S}$ rRNA gene. If no PCR product resulted, the primer pair ITS1F/ITS4 was used [23]. The detailed analysis followed the one published by Schirkonyer et al. [15]. 
Table 2. Primers used for PCR-RFLP.

\begin{tabular}{cc}
\hline ITS 1 (White et al. 1990): & 5'-TCCGTAGGTGAACCTGCGG-3' \\
ITS1F (Gardes und Bruns 1993): & 5'-CTTGGTCATTTAGAGGAAGTAA-3' \\
ITS4 (White et al. 1990): & 5'-TCCTCCGCTTATTGATATGC-3' \\
ITS 4B (Gardes und Bruns 1993): & 5'-CAGGAGACTTGTACACGGTCCAG-3' \\
\hline
\end{tabular}

\subsection{RNA Extraction}

Total RNA was extracted from mycorrhizal roots or fruiting bodies using the "NucleoSpin ${ }^{\circledR}$ RNA-Plant"-Kit, by Machery and Nagel (Düren, Germany). An amount of 50 to $100 \mathrm{mg}$ of fresh material was homogenized in a $1.5 \mathrm{ml}$ Eppendorf Safe tube with a micropistil under liquid nitrogen. The resulting homogenate was pipetted on ice into a microcentrifuge tube and $350 \mu \mathrm{l}$ "RAP"-buffer (guanidine- $\mathrm{HCl}$ lysis buffer) and $3.5 \mu \mathrm{l}$ 2-mercaptoethanol added, vortexing the mixture. The resulting lysate was pipetted on a "NucleoSpin ${ }^{\circledR ”}$-filter inserted into a collecting tube and then centrifuged for $1 \mathrm{~min}$ at $11,000 \times \mathrm{g}$ at room temperature. The filtrate was transferred into a microcentrifuge tube, $350 \mu \mathrm{l}$ ethanol (70\%) added and the mixture five times pipetted up and down. The resulting lysate was loaded on a "NucleoSpin ${ }^{\circledR}$-RNA-Plant" column and the unit centrifuged for $1 \mathrm{~min}$ at $11,000 \times \mathrm{g}$, to bind the total RNA (and DNA) to the silica membrane. Then the column was placed into a new collecting tube, $350 \mu \mathrm{l}$ "Membrane Desalting" buffer added to the column and the unit centrifuged for $1 \mathrm{~min}$ at $11,000 \times \mathrm{g}$, to desalt the membrane. Afterwards, $95 \mu \mathrm{l}$ DNase reaction mixture were applied onto the silica membrane of the column and the unit incubated at room temperature for 15 min to digest the bound DNA. Then, the silica membrane was washed adding $200 \mu$ " "RA2" buffer to the column and centrifuging the unit for $1 \mathrm{~min}$ at $11,000 \times \mathrm{g}$. Afterwards, the column was placed into a new collecting tube adding $600 \mu \mathrm{l}$ "RA3" solution to the column and centrifuging the unit for $1 \mathrm{~min}$ at $11,000 \times \mathrm{g}$. The flow-through was discarded and the column placed in the collecting tube again. Then, $250 \mu \mathrm{l}$ "RA3" buffer was added and the unit centrifuged for $2 \mathrm{~min}$ at $11,000 \times \mathrm{g}$. After that the column was put into a nuclease-free $1.5 \mathrm{ml}$ microcentrifuge tube. Total RNA was eluted from the membrane by adding $60 \mu \mathrm{l}$ RNase-free water followed by a 1 min lasting centrifugation at $11,000 \times \mathrm{g}$.

\subsection{0. cDNA Synthesis}

A first strand cDNA was synthesized by use of "The First Strand cDNA Synthesis-Kit" of Fermentas (St. Leon-Rot, Germany), annealing an oligo(dT) primer to the poly(A) tail of mRNAs. Into a microcentrifuge tube $14 \mu \mathrm{l}$ of purified total RNA and $1 \mu \mathrm{l}$ of oligo(dT) primer ( $100 \mathrm{pmol})$ were added, the mixture briefly vortexed and centrifuged for $2 \mathrm{sec}$ at $11,000 \times \mathrm{g}$. The RNA-primer mix was denatured at $70^{\circ} \mathrm{C}$ for $5 \mathrm{~min}$ and then placed on ice. Then, $5 \mu \mathrm{l} \mathrm{M}$-"MulV-5x RTase-buffer (250 mM Tris-HCl (pH 8.3), $375 \mathrm{mM} \mathrm{KCl,} 15 \mathrm{mM} \mathrm{MgCl}$ ), $2 \mu \mathrm{l}$ 
dNTP-mix (10 mM), $1 \mu \mathrm{l}$ "Ribbolock-RNAse inhibitor" and $1 \mu$ diethyl pyrocarbonate (DEPC)-water were added, and the mixture incubated for $60 \mathrm{~min}$ at $42^{\circ} \mathrm{C}$. A 10 minute incubation at $70^{\circ} \mathrm{C}$ terminated the reaction.

\subsection{Amplification of cDNA and DNA Dihydrolipoyl Dehydrogenase-Sequences}

The DNA sequence of the enzyme NADH diaphorase of Xerocomus badius and $X$. pruinatus associated with European beech or Norway spruce was amplified by use of the primer pair P1 and P2 (Table 3) while the primers Dia1-fw and Primer-rev1 were applied to amplify the corresponding cDNA sequences.

Primers were purchased from Eurofins MWG Operon (Ebersberg, Germany). The used Primers were deduced from partial cDNA sequences published at the Genbank NCBI for the basidiomycetes Ustilago maydis, Cryptococcus neoformans, Laccaria bicolor and the diaphorase sequence of the two basidiomycetes Xerocomus badius and Xerocomus pruinatus gained via genome sequencing [24]. To avoid pcr-products of the diaphorase enzymes belonging to the host trees the sequence of the plant Arabidopsis thaliana was integrated into the primer construction. Primers were designed from the aligned sequences of the above named organisms using the software Primer Premier (PREMIER Biosoft International, Palo Alto, USA). The dihydrolipoyl dehydrogenase gene sequence was amplified using a $20 \mu \mathrm{l}$ PCR mixture contained the following components: 2 $\mu \mathrm{l}$ of a $10 \times$ PCR-buffer, $2 \mu \mathrm{l} 2 \mathrm{mM}$ dNTP mix, $1 \mu \mathrm{l} 10$ pM Primer-fw1 or Primer-fw2, $1 \mu 10$ pM Primer-rev1 or Primer-rev2, $3.8 \mu$ l HPLC- $\mathrm{H}_{2} \mathrm{O}$ and $0.2 \mu \mathrm{l} 5$ $\mathrm{U} / \mu \mathrm{l}$ polymerase. Amplifications were performed by applying the following temperature program: 1) denaturation $\left(5 \min 94^{\circ} \mathrm{C}\right)$, 2) 35 cycles for amplification $\left(30 \mathrm{sec}\right.$ at $94^{\circ} \mathrm{C}, 1 \mathrm{~min}$ at $50^{\circ} \mathrm{C}, 2 \mathrm{~min}$ at $\left.\left.72^{\circ} \mathrm{C}\right), 3\right)$ final extension $(30 \mathrm{sec}$ at $94^{\circ} \mathrm{C}, 1 \mathrm{~min}$ at $50^{\circ} \mathrm{C}$ and $10 \mathrm{~min}$ at $72^{\circ} \mathrm{C}$ ) and 4 ) storage at $5^{\circ} \mathrm{C}$.

\subsection{Sequencing of PCR Products and Genome Sequencing}

Sequencing of PCR products and genome-sequencing of the fungi Xerocomus badius and $X$. pruinatus via Illumina HiSeq 2000 (Illumina 2006, San Diego, California, USA) was done by GENterprise-Genomics (Mainz, Germany). For fungal identification, BLAST searches were carried out against the public sequence databases NCBI (http://www.ncbi.nlm.nih.gov/) and UNITE (http://unite.ut.ee). Sequences were assigned to matching species names when the BLAST matches showed identities higher than 97\% and scores higher than 900 bits.

Table 3. Sequences of the primer pairs P1 and P2 and the primer DIA1-fw.

\begin{tabular}{ccc}
\hline P1 & Primer-fw1: & 5'-CTT CGG TCA CAC GTA TCC T-3' \\
& Primer-rev1: & 5'-CTC GCT GAG TGT GGG CTA-3' \\
& Primer-fw2: & 5'-CCA GTG ACA CCA CTT ACA-3' \\
P2 & 5'-TGA GTG TGG GCT AGA ATA GA-3' \\
& Primer-rev2: & 5'-G(AG)T TGA GGC (AC)AA GAA C(AG)T-3'
\end{tabular}


The name suggested by UNITE, a curated database for ectomycorrhizal fungi [25], was used preferentially and that of NCBI only if there was no entry in UNITE.

\section{Results and Discussion}

\subsection{Allozymes and Affiliation of Dihydrolipoyl Dehydrogenases}

Separation of native proteins extracted from mycorrhizae of European beech by Cellulose Acetate electrophoresis resulted in up to seven isozymes of the enzyme dihydrolipoyl dehydrogenase. The various isozymes were adjoined to four gene loci A, B', B and C (Figure 1). At the loci A, B' and C a single isozyme was observed that migrated, depending on the sample from which it was taken, somewhat faster or slower. Consequently, two alleles were adjoined to each of the three loci. The dihydrolipoyl dehydrogenase enzymes expressed at these loci are assumed to be homodimers. At locus B either one faster or slower migrating allozyme or three isozymes could be visualized after electrophoresis. The homozygotic states of the corresponding gene locus are expressing two homodimeric forms of the dihydrolipoyl dehydrogenase enzyme (B1 B1 and B2 B2) while the heterozygotic form leads to two homodimeric allozymes and one heterodimeric allozyme (B1 B1, B1B2 and B2 B2) (Figure 1).

In order to find out the affiliation of dihydrolipoyl dehydrogenase allozymes to tree roots and fungal hyphae respectively, ectomycorrhizae from European beech, Sessile oak, Norway spruce and European larch associated with the fungus Xerocomus pruinatus were investigated as well as rhizomorphae and fruiting bodies of that fungus. Additionally, non mycorrhizal root tips of European beech were analysed. It results that allozymes at locus $C$ exclusively stem from the fungus $X$. pruinatus (Figure 2). The fungus specific affiliation of locus $\mathrm{C}$ was

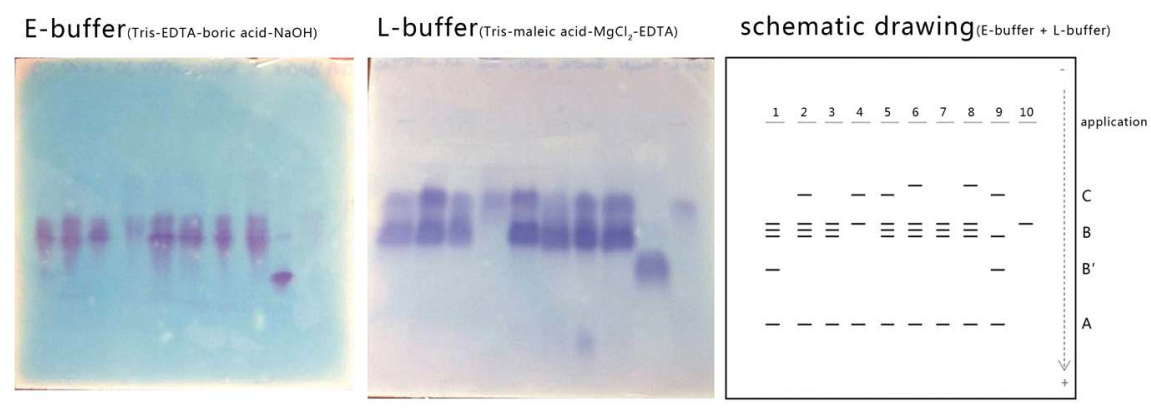

Figure 1. Allozyme patterns of dihydrolipoyl dehydrogenase enzymes visualized after Cellulose Acetate electrophoresis. Enzymes were extracted from ectomycorrhizae of European beech (Fagus sylvatica) associated with hyphae of the following fungi: Lactarius hepaticus, 2: Xerocomus pruinatus, 3: Paxillus spp., 4: Russula ochroleuca, 5: Fagirhiza spp. and 6, 7, 8, 10: Xerocomus pruinatus. Sample 9 represents an extract of root tips of Norway spruce (Picea abies) in symbiosis with Xerocomus badius. Single enzyme bands separated better upon electrophoresis in a Tris-EDTA-borate buffer of $\mathrm{pH} 8.9$, while the enzymes forming a complex of three enzymes were better resolved in a Tris-maleate- $\mathrm{MgCl}_{2}$-EDTA buffer of $\mathrm{pH}$ 7.8. 


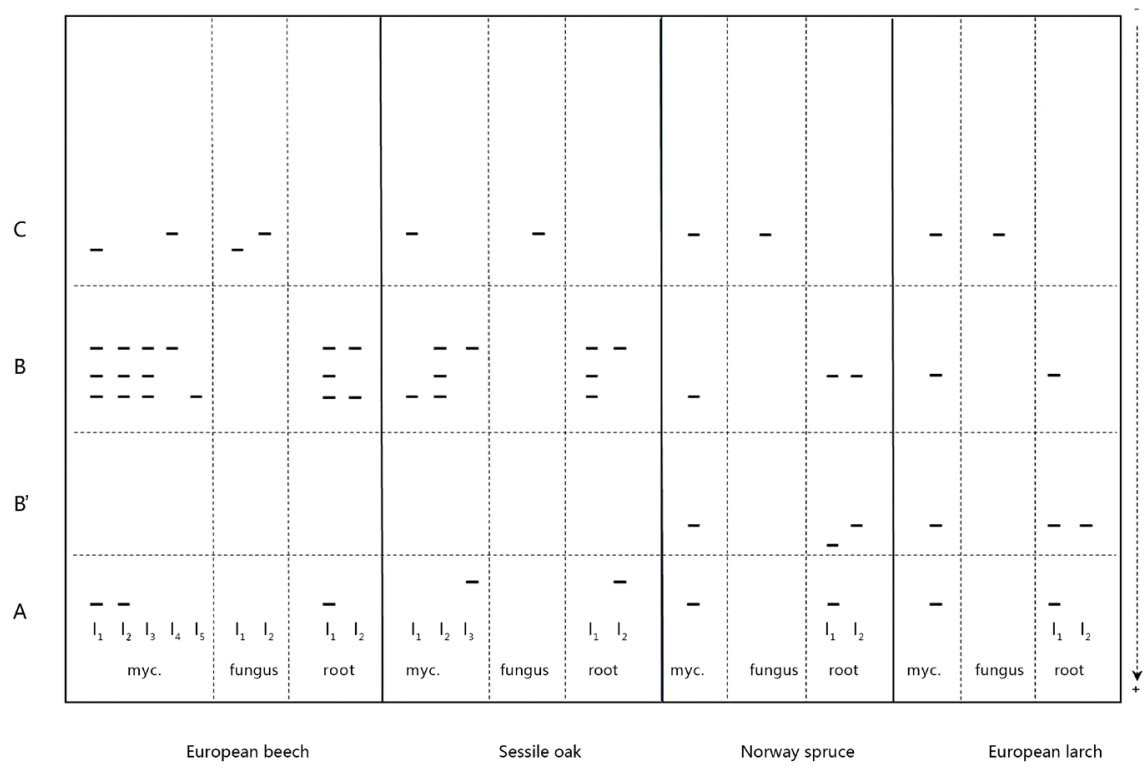

Figure 2. Scheme of dihydrolipoyl dehydrogenase patterns visualized on the separation medium Cellulose Acetate after electrophoresis. Myc: mycorrhizal root tips associated with Xerocomus pruinatus. Fungus: fruiting bodies, peeled off hyphae or rhizomorphae. Root: root tips of European beech seedlings grown in hydroculture or peeled fine roots without fungal hyphae.

also observed for the ectomycorrhizal fungi Lactarius spp., Paxillus involutus, Russula ochroleuca and Xerocomus badius in association with the same four host trees (Figure 3).

The loci A, B' and B are belonging to each of the four host trees. The deciduous trees European beech and Sessile oak are expressing loci A and B whereas the conifers Norway spruce and European larch possess in addition the active gene locus B' (Figure 2 and Figure 3).

In extracts of the ectomycorrhizal fungi Boletus edulis, Laccaria amethystina, Russula ochroleuca, Tylopilus felleus, Xerocomus badius and Xerocomus pruinatus only one active dihydrolipoyl dehydrogenase enzyme and one corresponding enzyme gene was observed. We assume that the enzyme is part of the two mitochondrial enzyme complexes pyruvate dehydrogenase (EC 1.2.4.1) and alpha-ketoglutarate dehydrogenase (EC 1.2.4.2). In contrast to these results we conclude the presence of two active dihydrolipoyl dehydrogenase genes within the deciduous tree species European beach and Sessile oak. Here, each of the two mitochondrial enzyme complexes pyruvate dehydrogenase and alpha-ketoglutarate dehydrogenase may contain a slightly differing form of the enzyme dihydrolipoyl dehydrogenase. The two conifers Norway spruce and European larch which function as hosts for ectomycorrhizal fungi are expressing three dihydrolipoyl dehydrogenase gene loci. Provided the corresponding enzyme forms result from two, respectively three different enzyme loci, upon the evolution of the deciduous trees from conifers one of the corresponding enzyme genes may have been silenced. Histochemical stainings that served to visualize dihydrolipoyl 
European beech

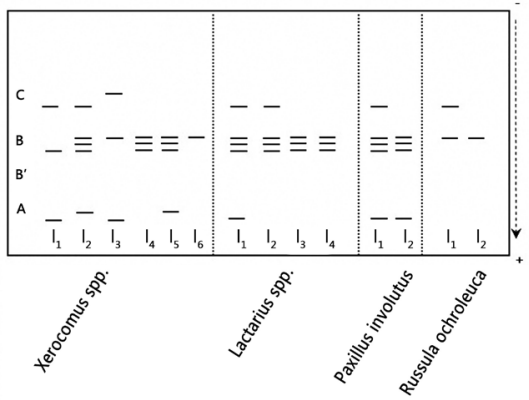

Norway spruce

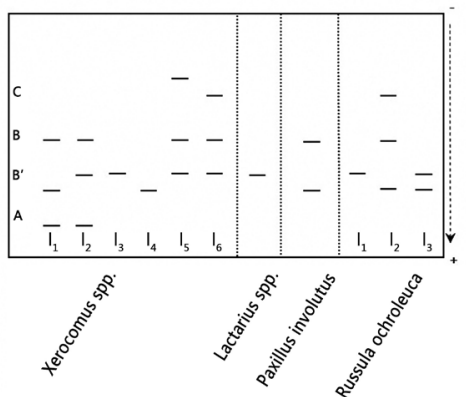

Sessile oak

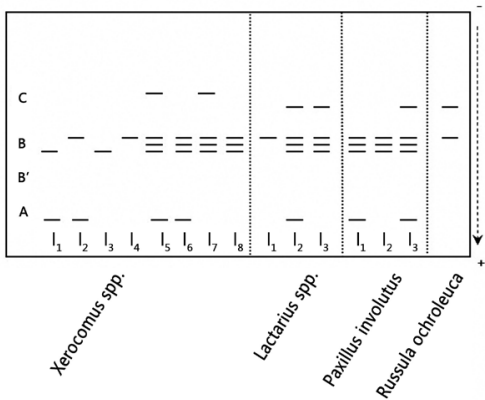

European larch

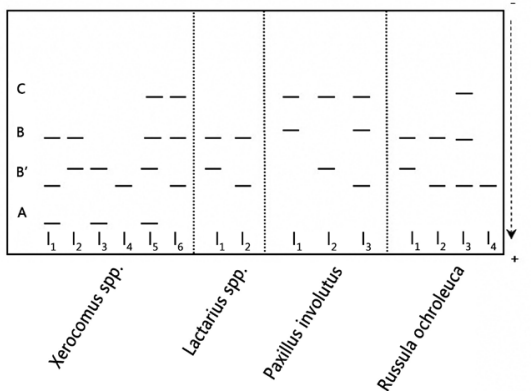

Figure 3. Allozyme pattern of NADH-diaphorase in different ectomycorrhizal fungi in symbiosis with beech, oak, spruce and larch. (I1, I2 .. = individuals).

dehydrogenase activities showed that the enzyme was more active in hyphae of Xerocomus badius than in those of $X$. pruinatus. Kinetic analyses lead to corresponding results. Differing activities were also observed between the ectomycorrhizal species Cenococcum geophilum, Scleroderma citrium, Paxillus involutus and Pisolitus tinctorius [26].

\subsection{Molecular Genetic Analyses}

The DNA of Xerocomus pruinatus and X. badius was analyzed by use of "The Next-Generation-Illumina sequencing-method" (Solexa/Illumina, Berlin, (performed by GENterprise-Genomics, Mainz University). After the genome had been sequenced, localized primers were deduced as described in chapter 2.11 in order to amplify the gene sequence of the dihydrolipoyl dehydrogenase gene.

The full length of the dihydrolipoyl dehydrogenase gene has a length of 1631bp (cDNA: $1370 \mathrm{bp}+(5$ Introns $=261 \mathrm{bp})$ in Xerocomus badius and 1721 (cDNA: $1460 \mathrm{bp}+261 \mathrm{bp}$ ) in X. pruinatus (cf. sequences listed at the Appendix). The DNA sequences of the dihydrolipoyl dehydrogenase gene isolated from Xerocomus pruinatus and X. badius resemble those of other fungi deposited at the NCBI-gene bank to $70 \%$ to $78 \%$ (Table 4 ).

Five introns, each having a length of $52 \mathrm{bp}$, could be localized comparing the full gene length with that of the cDNA length (Table 5).

The gene sequences of the dihydrolipoyl dehydrogenase enzymes existing within the ectomycorrhizal fungi Boletus edulis, Laccaria amethystina, Paxillus 
Table 4. Similarity of the genomic sequence of the dihydrolipoyl dehydrogenase of $X e$ rocomus pruinatus and $X$. badius in comparison to other fungi.

\begin{tabular}{ccccc}
\hline $\begin{array}{c}\text { Xerocomus } \\
\text { pruinatus }\end{array}$ & $\begin{array}{c}\text { \% similarity compared to } \\
\text { X. pruinatus }\end{array}$ & 99 & Xerocomus badius & \% similarity compared to \\
\cline { 1 - 2 } X. badius & 90 & X. badius & 90 \\
Cryptococcus & 78 & Cryptococcus & 78 \\
neoformans & & neoformans & \\
Coprinus cinerea & 75 & Ustilago maydis & 76 \\
Laccaria bicolor & 75 & Coprinus cinerea & 74 \\
Cryptococcus gatti & 71 & Laccaria bicolor & 74 \\
Ustilago maydis & 70 & Cryptococcus gatti & 71 \\
\hline
\end{tabular}

Table 5. Position and length of the five introns of the dihydrolipoyl dehydrogenase gene in Xerocomus badius and $X$. pruinatus.

\begin{tabular}{ccc}
\hline Intron number & Sequence range & Size $(\mathrm{bp})$ \\
\hline 1 & $295-347$ & 52 \\
2 & $485-538$ & 53 \\
3 & $985-1037$ & 52 \\
4 & $1172-1224$ & 52 \\
5 & $1691-1743$ & 52 \\
\hline
\end{tabular}

involutus and Russula ochroleuca also include five $52 \mathrm{bp}$ long introns located at the regions of the Xerocomus gene. These observations are in accordance with reports concerning the gene structure of the basidiomycetes Cryptococcus gatti, Cryptococcus neoformans, Coprinus cinerea, Ustilago maydis and Laccaria bicolor and the ascomycetes Candida albicans, C. orthopsilosis, Mycosphaerella graminicola and Trichophytum rubrum deposited at the Gene Bank (NCBI). The coding sequence of the gene of $X$. pruinatus deviates at 144 positions from that of $X$. badius. Besides the single nucleotide polymorphisms, the $X$. pruinatus gene contains a $48 \mathrm{bp}$ long sequence at the positions 200 to 248 that could not be proved for the DNA and cDNA sequences of the gene from $X$. badius. Altogether, the two gene sequences deviate at 192 positions, which makes $11 \%$. The number of single nucleotide polymorphisms of the five introns of $X$. badius and $X$. pruinatus sum up to $74 \mathrm{bp}$, corresponding to a deviation of $28.5 \%$. Consequently, the nucleotide deviations in the five intron areas are about three times higher than those within the coding regions. The host trees European beech and Norway spruce did not influence the dihydrolipoyl dehydrogenase gene sequences in the two Xerocomus species.

\subsection{Protein Structures}

The cDNA sequences of the dihydrolipoyl dehydrogenases from the two Xero- 
comus species served to determine their amino acid sequences (Figure 4 and Figure 5).

The number of positively charged amino acid residues (Arg and Lys) within the enzyme of $X$. pruinatus makes 79 while it makes 68 in $X$. badius. The number of negatively charged amino acids (Asp and Glu) makes 46 in $X$. pruinatus and 48 in $X$. badius. Molecular weights and isoelectric points were determined by use of the software ExPASy- "Protparam" (https://web.expasy.org/protparam/) (Table 6).

The length of cDNA of the dihydrolipoyl dehydrogenase gene of the basidiomycete Coprinopsis cinerea makes 1527 bp, corresponding to 494 amino acids [27]. The cDNA length of the gene of the fungus Laccaria bicolor makes $1593 \mathrm{bp}$, which equals 514 amino acids [28]. The dihydrolipoyl dehydrogenase enzyme of the yeast Saccharomyces cerevisiae comprises 487 amino acids and its molecular

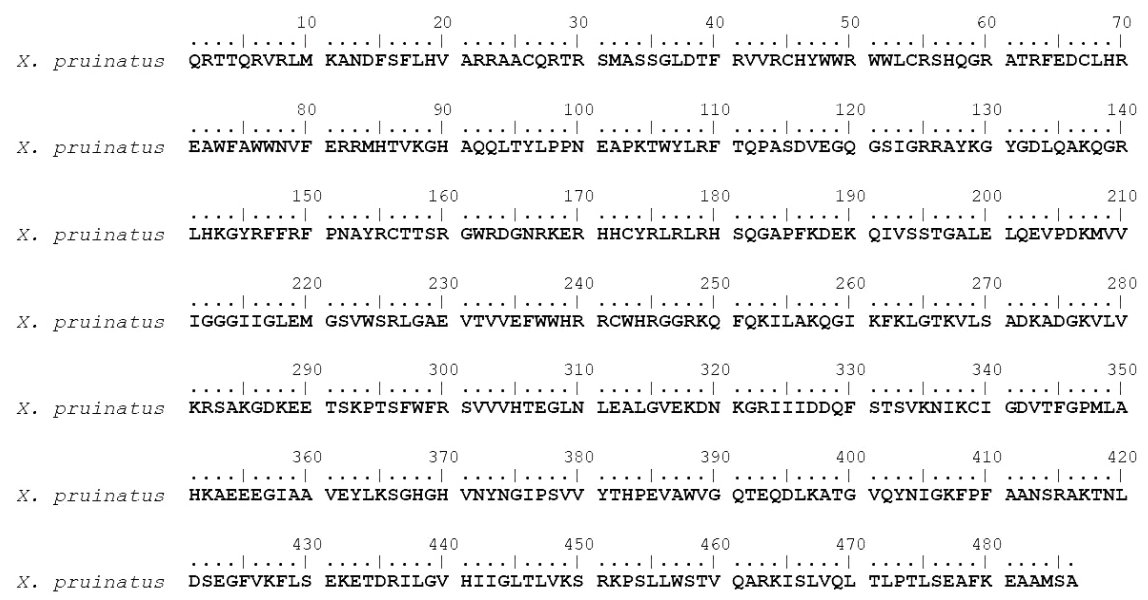

Figure 4. Amino acid sequences of the dihydrolipoyl dehydrogenase gene of Xerocomus pruinatus.

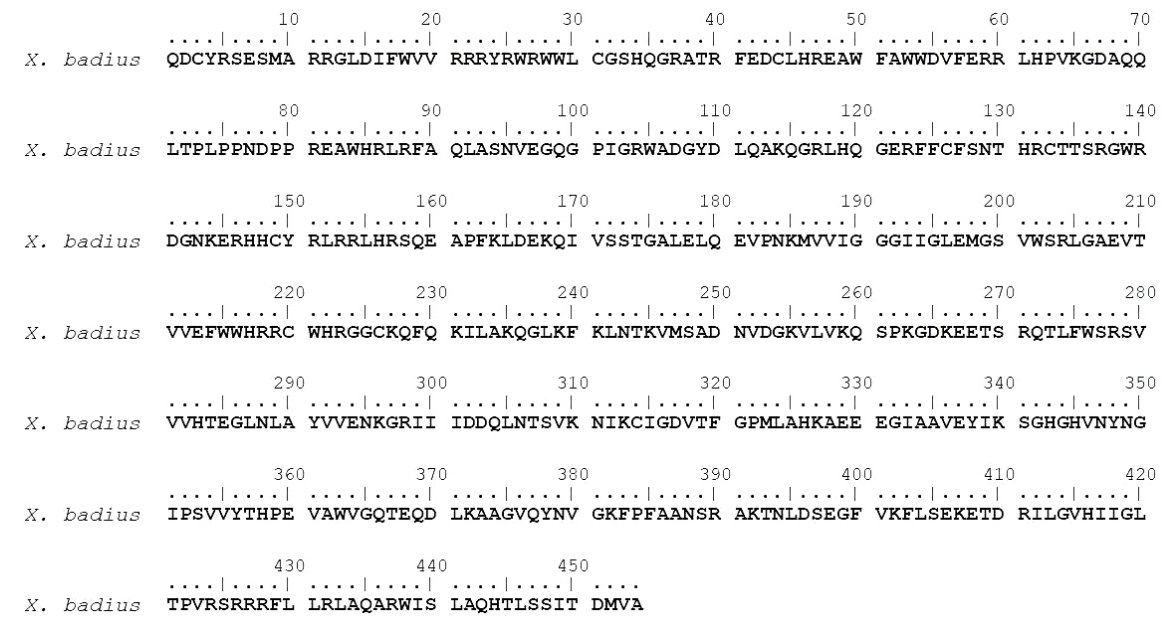

Figure 5. Amino acid sequences of the dihydrolipoyl dehydrogenase gene of the fungus Xerocomus badius. 
mass makes $51558 \mathrm{Da}$ [29]. In most organisms, the enzyme represents a homodimer with a monomeric molecular weight of 50 to $55 \mathrm{kDa}$ (Data Bank BRENDA, https://www.brenda-enzymes.org/index.php). Crystallographic studies of the human enzyme dihydrolipoyl dehydrogenase lead to the conclusion that its amino acid sequence contains four functional domains: an NADH domain within a larger FAD domain, a central domain and a dimerization domain at its C-terminal end [30]. This result was confirmed for the bacterial, fungal and plant enzyme [31]. Comparing the amino acid sequences of the dihydrolipoyl dehydrogenase enzymes of several fungi with those of the two Xerocomus species, we conclude that within the latter the range from amino acid 207 to 281 represents a short NADH binding site being part of a larger FAD-binding domain. The second highly conserved region is located at the C-terminal end and ranges from amino acid 375 to 485 making the binding/dimerization domain. These domains are characteristic for pyridine nucleotide-disulfide oxidoreductases (InterPro Protein sequence analysis \& classification; http://www.ebi.ac.uk/interpro/entry/IPR012999). By use of the SWISS-MODEL a fully automated protein structure homology-modelling server, accessible via ExPASy web server, the 3D-structure of the Xerocomus badius enzyme (454 amino acids) and $X$. pruinatus (486 amino acids) could be evaluated (Figure 6). The amino acid chains deviate by 32 amino acids but the 3D structures are congruent.

Altogether calculations resulted in 27.4 alpha helices, $24.8 \%$ beta strand structures, $11.9 \%$ beta loops and 35.9\% other windings SWISS-Model [32] [33] [34] [35].

Table 6. Number of nucleotides and number of amino acids, molecular weights and isoelectric points of the enzyme dihydrolipoyl dehydrogenase of Xerocomus pruinatus and $X$. badius.

\begin{tabular}{|c|c|c|c|c|c|}
\hline \multirow[t]{2}{*}{ Species } & \multicolumn{2}{|c|}{ Nucleotides (bp) } & \multirow[t]{2}{*}{ Amino acids } & \multirow[t]{2}{*}{$\begin{array}{l}\text { Molecular weight } \\
\text { (Da) }\end{array}$} & \multirow[t]{2}{*}{$\begin{array}{c}\text { calculated isoelectric } \\
\text { point }\end{array}$} \\
\hline & DNA & cDNA & & & \\
\hline $\begin{array}{c}\text { Xerocomus } \\
\text { pruinatus }\end{array}$ & 1721 & 1460 & 486 & 55537.6 & 9.99 \\
\hline $\begin{array}{c}\text { Xerocomus } \\
\text { badius }\end{array}$ & 1631 & 1370 & 454 & 52163.5 & 9.68 \\
\hline
\end{tabular}
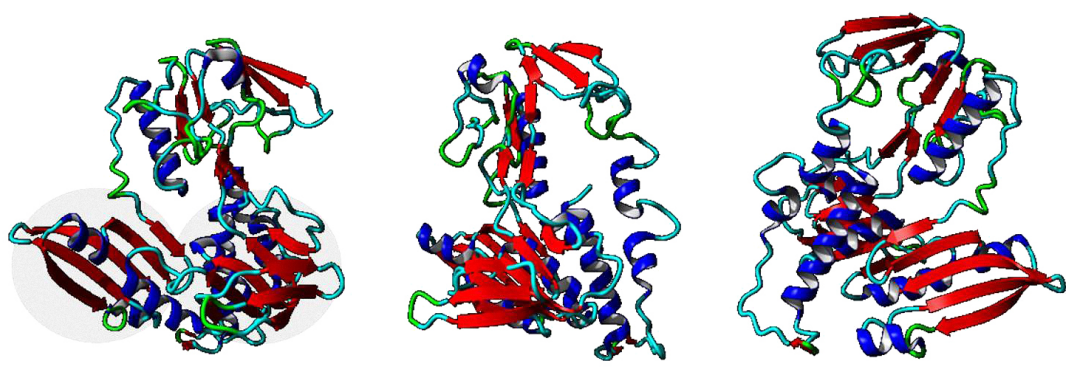

(a) 

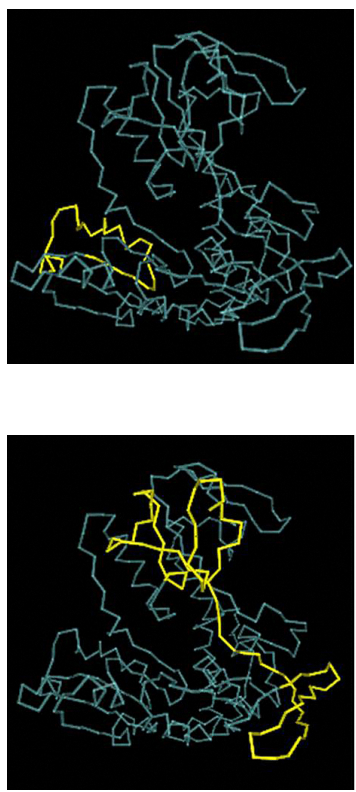

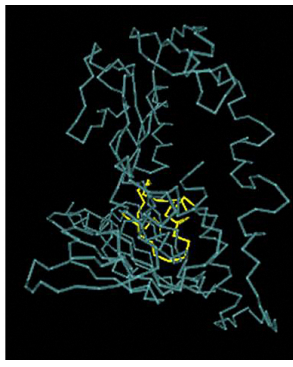

(b)

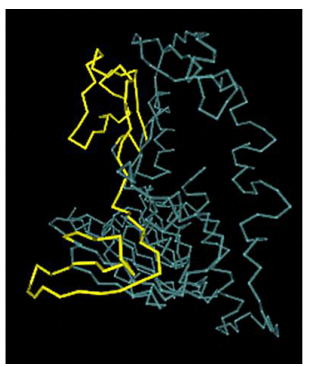

(c)
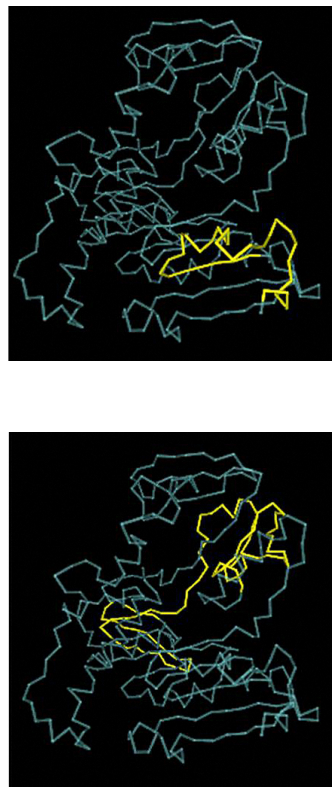

Figure 6. (a) 3D structure of the enzyme NADH-diaphorase from the ectomycorrhiza fungi Xerocomus badius and Xerocomus pruinatus. One and the same 3D structure is represented from different angles. (grey background $=$ large $\beta$-sheet areas, blue $=\alpha$-helix, red $=\beta$-sheet, turquoise $=$ random coil). The $3 \mathrm{D}$ schemes were displayed and colored in YASARA View (http://www.yasara.org/); (b) Dimerization site at the C-terminal end of the enzyme NADH-diaphorase from the ectomycorrhiza fungi Xerocomus badius and Xerocomus pruinatus; (c) NADH-binding site of the enzyme NADH-diaphorase from the ectomycorrhiza fungi Xerocomus badius and Xerocomus pruinatus.

\section{References}

[1] Anderson, I.C. and Cairney, J.W.G. (2007) Ectomycorrhizal Fungi: Exploring the Mycelial Frontier. FEMS Microbiology Reviews, 31, 388-406.

https://doi.org/10.1111/j.1574-6976.2007.00073.x

[2] Smith, S.E. and Read, D.J. (2008) Mycorrhizal Symbiosis. 3rd Edition, Academic Press, Amsterdam, Boston.

[3] Steffens, F., Arendholz, W.-R. and Storrer, J.G. (1994) Ectomycorrhiza: A Symbiosis under the Magnifying Glass. Biologie in unserer Zeit, 24, 211-218.

[4] Agerer, R. (1991) Characterization of Ectomycorrhizae. In: Norris, J.R., Read, D.J. and Varma, A.K., Eds., Techniques for the Study of Mycorrhizae, Methods in Microbiology, Vol. 23, Academic Press, London, 25-73. https://doi.org/10.1016/S0580-9517(08)70172-7

[5] Agerer, R. (1987-2002) Colour Atlas of Ectomycorrhizae: With Glossary. Einhorn-Verlag, Schwäbisch.

[6] Lindahl, B.D., Finlay, R.D. and Cairney, J.W.G. (2005) Enzymatic Activities of Mycelia in Mycorrhizal Fungal Communities. In: Dighton, J., Oudemans, P. and White, J., Eds., The Fungal Community, Its Organization and Role in the Ecosystem, Marcel Dekker, New York, 331-348.

[7] Leake, J.R. and Read, D.J. (1990) Chitin as a Nitrogen Source for Mycorrhizal Fungi. Mycological Research, 94, 993-995. https://doi.org/10.1016/S0953-7562(09)81318-X

[8] Burns, R.G. and Dick, R.P. (2002) Enzymes in the Environment: Activity, Ecology, 
and Applications. CRC Press, Boca Raton. https://doi.org/10.1201/9780203904039

[9] Bartlett, E.M. and Lewis, D.H. (1973) Surface Phosphatase Activity of Mycorrhizal Roots of Beech. Soil Biology and Biochemistry, 5, 249-257. https://doi.org/10.1016/0038-0717(73)90008-4

[10] Arvieu, J.C., Leprince, F. and Plassard, C. (2003) Release of Oxalate and Protons by Ectomycorrhizal Fungi in Response to P-Deficiency and Calcium Carbonate in $\mathrm{Nu}$ trient Solution. Annals of Forest Science, 60, 815-821. https://doi.org/10.1051/forest:2003076

[11] Rothe, G.M. (2015) Organisms More than Chemistry. Verlag Dr. Kovač, Hamburg.

[12] Phillips, R. (1998) The Great Cosmos Nature Guide for Mushrooms-Over 900 Indigenous Species of Mushrooms in Colors. Franck-Kosmos Verlag, Stuttgart.

[13] Kriegelsteiner, G.J., Gminder, A., Winterhoff, W. and Kaiser, A. (2000) Die Grosspilze Baden-Württembergs: 2. Ständerpilze: Leisten-, Keulen-, Korallen-und Stoppelpilze, Bauchpilze, Röhrlings-und Täublingspilzartige. [Large Mushrooms of Baden-Wuerttemberg: 2. Basidiomycota: ...]. Eugen Ulmer Verlag, Stuttgart.

[14] Haese, A. and Rothe, G.M. (2003) Characterization and Frequencies of the IGS1 Alleles of the Ribosomal DNA of Xerocomus pruinatus Mycorrhizae. Forest Genetics, 10, 103-110.

[15] Schirkonyer, U., Bauer, C. and Rothe, G.M. (2013) Ectomycorrhizal Diversity at Five Different Tree Species in Forests of the Taunus Mountains in Central Germany. Open Journal of Ecology, 3, 66-81.

https://doi.org/10.4236/oje.2013.31009

[16] Fiedler, O. (1997) Isoenzymatic Investigations on Beech Mycorrhizae of Xerocomus chrysenteron. Diploma Thesis, Department of Biology, University of Mainz, Mainz.

[17] Richardson, B.I., Baverstock, P.R. and Adams, M. (1986) Allozyme Electrophoresis. A Handbook for Animal Systematics and Population Studies. Academic Press, San Diego.

[18] Hebert, P.D.N. and Beaton, M.J. (1993) Methodologies for Allozyme Analysis Using Cellulose Acetate Electrophoresis. A Practical Handbook. Helena Laboratories, Texas.

[19] Rothe, G.M. (1994) Electrophoresis of Enzymes. Laboratory Methods. Springer Verlag, Berlin, Heidelberg. https://doi.org/10.1007/978-3-642-79069-0

[20] Yan, L.-J., Yang, S.-H., Shu, H., Prokai, L. and Forster, M.J. (2007) Histochemical Staining and Quantification of Dihydrolipoamide Dehydrogenase Diaphorase Activity Using Blue Native PAGE. Electrophoresis, 28, 1036-1045. https://doi.org/10.1002/elps.200600574

[21] Doyle, J.J. and Doyle, J.L. (1987) A Rapid DNA Isolation Procedure for Small Quantities of Fresh Leaf Tissue. Phytochemical Bulletin, 19, 11-15.

[22] White, T., Bruns, T., Lee, S. and Tayler, J. (1990) Amplification and Direct Sequencing of Fungal Ribosomal RNA Genes for Phylogenetics. In: Innis, M., Gelfand, D., Shinsky, J. and White, T., Eds., PCR Protocols: A Guide to Methods and Applications, Academic Press, Cambridge, 315-322. https://doi.org/10.1016/B978-0-12-372180-8.50042-1

[23] Gardes, M. and Bruns, T.D. (1993) ITS Primers with Enhanced Specificity for Basidiomycetes: Application to the Identification of Mycorrhizae and Rusts. Molecular Ecology, 2, 113-118. https://doi.org/10.1111/j.1365-294X.1993.tb00005.x

[24] Schirkonyer, U. (2014) Molecular Biological Investigations of the Enzyme NADH-Diaphorase in Mycorrhizal Fungi of the Genus Xerocomus and Investiga- 
tion of the Diversity of Their Accompanying Species in Forest Ecosystems of the Taunus Mountains. WestarpWissenschaften, Hohenwarsleben.

[25] Kõljalg, U., Larsson, K.-H., Abarenkov, K., Nilsson, R.H., Alexander, I.J., Eberhardt, U., Erland, S., Høiland, K., Kjøller, R., Larsson, E., Pennanen, T., Sen, R., Taylor, A.F.S., Tedersoo, L., Vrålstad, T. and Ursing, B.M. (2005) UNITE: A Database Providing Web-Based Methods for the Molecular Identification of Ectomycorrrhizal Fungi. New Phytologist, 166, 1063-1068. https://doi.org/10.1111/j.1469-8137.2005.01376.x

[26] Cao, W. and Crawford, D.L. (1993) Carbon Nutrition and Hydrolytic and Cellulolytic Activities in the Ectomycorrhizal Fungus Pisolithustinctorius. Canadian Journal of Microbiology, 39, 529-535. https://doi.org/10.1139/m93-075

[27] Stajich, J.E., Wilke, S.K., Ahrén, D., Au, C.H., Birren, B.W., Borodovsky, M., Burns, C., Canbäck, B., Casselton, L.A., Cheng, C.K., et al. (2010) Insight into Evolution of Multicellular Fungi from the Assembled Chromosomes of the Mushroom Coprinuscinerea (Coprinuscinereus). Proceedings of the National Academy of Sciences, 107, 11889-11894. https://doi.org/10.1073/pnas.1003391107

[28] Martin, F., Aerts, A., Ahrén, D., Brun, A., Danchin, E.G., Duchaussoy, F., Gibon, J., Kohler, A., Lindquist, E., Pereda, V., et al. (2008) The Genome of Laccariabicolor Provides Insights into Mycorrhizal Symbiosis. Nature, 452, 88-92.

https://doi.org/10.1038/nature06556

[29] Browning, K.S., Uhlinger, D.J. and Reed, L.J. (1988) Nucleotide Sequence for the Yeast Dihydrolipoamide Dehydrogenase. Proceedings of the National Academy of Sciences, 85, 1831-1834. https://doi.org/10.1073/pnas.85.6.1831

[30] Brautigam, C.A., Chuang, J.L., Tomchick, D.R., Machius, M. and Chuang, D.T. (2005) Crystal Structure of Human Dihydrolipoamide Dehydrogenase: $\mathrm{NAD}+/ \mathrm{NADH}$ Binding and the Structural Basis of Disease-Causing Mutations. Journal of Molecular Biology, 350, 543-552. https://doi.org/10.1016/j.jmb.2005.05.014

[31] Ciszak, E.M., Makal, A., Hong, Y.S., Vettaikkorumakankauv, A.K., Korotchkina, L.G. and Patel, M.S. (2006) How Dihydrolipoyl Dehydrogenase-Binding Protein Binds Dihydrolipoamide Dehydrogenase in the Human Pyruvate Dehydrogenase Complex. The Journal of Biological Chemistry, 281, 648-655. https://doi.org/10.1074/jbc.M507850200

[32] Arnold, K., Bordoli, L., Kopp, J. and Schwede, T. (2006) The SWISS-MODEL Workspace: A Web-Based Environment for Protein Structure Homology Modelling. Bioinformatics, 22, 195-201. https://doi.org/10.1093/bioinformatics/bti770

[33] Kiefer, F., Arnold, K., Künzli, M., Bordoli, L. and Schwede, T. (2009) The SWISS-MODEL Repository and Associated Resources. Nucleic Acids Research, 37, D387-D392. https://doi.org/10.1093/nar/gkn750

[34] Guex, N., Peitsch, M.C. and Schwede, T. (2009) Automated Comparative Protein Structure Modeling with SWISS-MODEL and Swiss-PdbViewer: A Historical Perspective. Electrophoresis, 30, S162-S173. https://doi.org/10.1002/elps.200900140

[35] Biasini, M., Bienert, S., Waterhouse, A., Arnold, K., Studer, G., Schmidt, T., Kiefer, F., Cassarino, T.G., Bertoni, M., Bordoli, L. and Schwede, T. (2014) SWISS-MODEL: Modelling Protein Tertiary and Quaternary Structure Using Evolutionary Information. Nucleic Acids Research, 42, W252-W258. 


\section{Appendix}

X. pruinatus-F.s.-DNA-P1

X.p.-P.a.-DNA-P2

X.p. -F.s.-cDNA-P1

X.p.-P.a.-CDNA-P2

X.badius-F.s.-DNA-P1

X.b.-P.a.-DNA-P2

X.b. -F.s.-CDNA-P1

X.b.-P.a.-CDNA-P2

X. pruinatus-F.s.-DNA-P1

$\mathrm{X} \cdot \mathrm{p} .-\mathrm{P} \cdot \mathrm{a},-\mathrm{DNA}-\mathrm{P} 2$

X.p. -F.s.-CDNA-P1

X.p.-P.a.-CDNA-P2

$\mathrm{X}$.badius-F.s.-DNA-P1

X.b.-P.a.-DNA-P2

X.b.-F.s.-CDNA-P1

X.b.-P.a.-CDNA-P2

X. pruinatus-F.s.-DNA-P1

X.p.-P.a.-DNA-P2

X.p.-F.s.-cDNA-P1

X.p.-P.a.-CDNA-P2

X.badius-F.s.-DNA-P1

X.b.-P.a.-DNA-P2

X.b. -F.s.-CDNA-P1

X.b.-P.a.-CDNA-P2

X. pruinatus-F.s.-DNA-P1

X.p.-P.a.-DNA-P2

X.p. -F.s.-CDNA-P1

X.p.-P.a.-CDNA-P2

X.badius-F.s.-DNA-P1

X.b.-P.a.-DNA-P2

X.b.-F.s.-CDNA-P1

X.b.-P.a.-CDNA-P2

X. pruinatus-F.s.-DNA-P1

X.p.-P.a.-DNA-P2

X.p. -F.s.-CDNA-P1

X.p.-P.a.-CDNA-P2

X.badius-F.s.-DNA-P1

X.b.-P.a.-DNA-P2

X.b.-F.s.-CDNA-P1

X.b.-P.a.-CDNA-P2

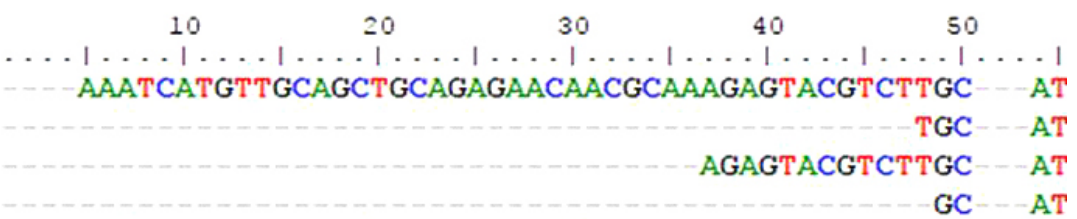

CATTGCTACGTGTTGCAGCTGCAGAGAGTCACGAAAAAAGTAAGTCTTGCACAAT

GCACAAT

AAGTAAGTCTTGCACAAT TTGCACAAT
80
90
100
110
120

$\ldots|\ldots| \ldots|\ldots| \ldots|\ldots| \ldots|\ldots| \ldots|\ldots| \ldots|\ldots| \ldots|\ldots|$ TTCCTGACATTTTTGTAGCACGTCGCACGGCGGCTGCGGCATGCCAGCGTTCAAC TTCCTGACATTTTTGTAGCACGTCGCACGGCGGCTGCGGCATGCCAGCGTTCAAC TTCCTGACATTTTTGTAGCACGTCGCACGGCGGCTGCGGCATGCCAGCGTTCAAC TTCCTGACATTTTTGTAGCACGTCGCACGGCGGCTGCGGCATGCCAGCGTTCAAC CACTT-ACATTTCTGCAGCAGATCGCACGGCGGTTGCGGCATGCTACCGTTCAAG CACTT-ACATTTCTGCAGCAGATCGCACGGCGGTTGCGGC-TGCTACCGTTCAA. CACTT-ACATTTCTGCAGCAGATCGCACGGCGGTTGCGGC-TGCTACCGTTCAA CACTT-ACATTTCTGCAGCAGATCGCACGGCGGTTGAGAC-TGCTACCGTTCAA

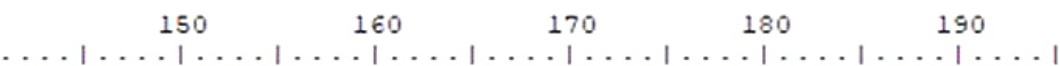
CTCACCGTGGACTTGCGACACCTTCCGGGTCGTATGACGCTGTCATTATTGGTGG CTCACCGTGGACTTGCGACACCTTCCGGGTCGTATGACGCTGTCATTATTGGTGG CTCACCGTGGACTTGCGACACCTTCCGGGTCGTATGACGCTGTCATTATTGGTGG CTCACCGTGGACTTGCGACACCTTCCGGGTCGTATGACGCTGTCATTATTGGTGG GCCACCTCGGACTCGGGACACCTTCTGGGTCGTATGACGCCGTCGTTATTGGTGG GCGACCTCGGACTCGGGACACCTTCTGGGTCGTATGACGCCGTCGTTATTGGTGG GCCACCTCGGACTCGGGACACCTTCTGGGTCGTATGACGCCGTCGTTATTGGTGG GCGACCTCGGACTCGGGACATCTTCTGGGTGGTATGACGCCGTCGTTATTGGTGG

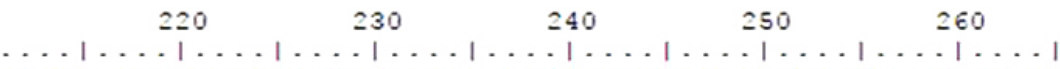
CTCAAACGGATGGCGTGTTTTGACCACTGCTGTAGGCCCTGGTGGTTATGTCGCA CTCAAACGGATGGCGTGTTTTGACCACTGCTGTAGGCCCTGGTGGTTATGTCGCA CCTGGTGGTTATGTCGCA CCTGGTGGTTATGTCGCA CCTGGTGGTTATGTGGCA CCTGGTGGTTATGTGGCA CCTGGTGGTTATGTGGCA CCTGGTGGTTATGTGGCA
290
300
310
320
330

$\ldots|\ldots| \ldots|\ldots| \ldots|\ldots| \ldots|\ldots| \ldots|\ldots| \ldots|\ldots| \ldots \mid$ CAACTCGGTTTGAAGGTATCCGGATCATCCGTGTCACCCG CGCGCTCTTA CAACTCGGTTTGAAGGTATCCGGATCATCCGTGTCACCCG CGCGCTCTTA CAACTCGGTTTGAA CAACTCGGTTTGAA Intron 1

CAACTCGGTTTGAAGGTAACCGGATCATGCGTTTCTTTCGTAACACTCCCGCTGA CAACTCGGTTTGAAGGTAACCGGATCATGCGTTTCTTTCGTAACACTCCCTCTGA CAACTCGGTTTGAA CAACTCGGTTTGAA

Intron 1 
X. pruinatus-F.s.-DNA-P1 $\mathrm{X} \cdot \mathrm{p},-\mathrm{P} \cdot \mathrm{a},-\mathrm{DNA}-\mathrm{P} 2$

X.p. -F.s.-CDNA-P1

X.p.-P.a.-CDNA-P2

X.badius-F.s.-DNA-P1

X.b.-P.a.-DNA-P2

X.b.-F.s.-CDNA-P1

X.b.-P.a.-CDNA-P2

X. pruinatus-F.s.-DNA-P1

X.p.-P.a.-DNA-P2

X.p. -F.s.-CDNA-P1

X.p.-P.a.-CDNA-P2

X.badius-F.s.-DNA-P1

X.b.-P.a.-DNA-P2

X.b. -F.s.-CDNA-P1

X.b.-P.a.-CDNA-P2

X. pruinatus-F.s.-DNA-P1

X.p. - P.a.-DNA-P2

X.p.-F.s.-CDNA-P1

X.p.-P.a.-CDNA-P2

X.badius-F.s.-DNA-P1

X.b.-P.a.-DNA-P2

X.b.-F.s.-CDNA-P1

X.b.-P.a.-CDNA-P2

X. pruinatus-F.s.-DNA-P1

X.p. - P.a.-DNA-P2

X.p. -F.s.-CDNA-P1

X.p.-P.a.-CDNA-P2

X.badius-F.s.-DNA-P1

X.b.-P.a.-DNA-P2

X.b. -F.s.-CDNA-P1

X.b.-P.a.-CDNA-P2

X. pruinatus-F.s.-DNA-P1

X.p.-P.a.-DNA-P2

X.p. -F.s.-CDNA-P1

X.p.-P.a.-CDNA-P2

X.badius-F.s.-DNA-P1

X.b. - P.a. -DNA-P2

X.b.-F.s.-cDNA-P1

X.b.-P.a.-CDNA-P2
360

370

380

390

400

$\ldots|\ldots| \ldots|\ldots| \ldots|\ldots| \ldots|\ldots| \ldots|\ldots| \ldots|\ldots| \ldots \mid$ CTGCTTGCATCGAGAAGCGTGGTTCGCTTGGTGGAACGTGTTTGAACGTCGGATG CTGCTTGCATCGAGAAGCGTGGTTCGCTTGGTGGAACGTGTTTGAACGTCGGATG CTGCTTGCATCGAGAAGCGTGGTTCGCTTGGTGGAACGTGTTTGAACGTCGGATG CTGCTTGCATTGAGAAGCGTGGTTCGCTTGGTGGAACGTGTTTGAACGTCGGATG CTGCTTGCATCGAGAAGCGTGGTTCGCTTGGTGGGACGTGTTTGAACGTCGGCTG CTGCTTGCATCGAGAAGCGTGGTTCGCTTGGTGGGACGTGTTTGAACGTCGGCTG CTGCTTGCATCGAGAAGCGTGGTTCGCTTGGTGGGACGTGTTTGAACGTCGGCTG CTGCTTGCATCGAGAAGCGTGGTTCGCTTGGTGGGACGTGTTTGAACGTCGGCTG

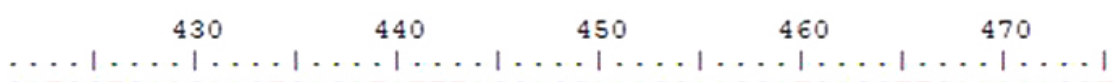
CATGCTCAACAACTCACATATTTACCACCAAACGAAGCATGACCTTGAAAAACGT CATGCTCAACAACTCACATATTTACCACCAAACGAAGCATGACCTTGAAAAACGT CATGCTCAACAACTCACATATTTACCACCAAACGAAGCATGACCTTGAAAAACGT CATGCT CAACAACTCACATATTTACCACCAAACGAAGCATGACCTTGAAAAACGT GATGCT CAACAACTCACACCTTTACCACCAAACGATCCATGACCTCGAGAAGCGT GATGCTCAACAACTCACACCTTTACCACCAAACGATCCATGACCTCGAGAAGCGT GATGCTCAACAACTCACACCTTTACCACCAAACGATCCATGACCTCGAGAAGCGT GATGCTCAACAACTCACACCTTTACCACCAAACGATCCATGACCTCGAGAAGCGT

$500 \quad 510 \quad 520 \quad 530 \quad 540$

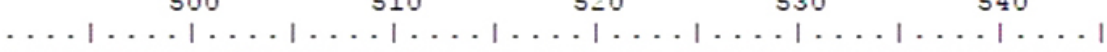
CAATGTTCGCCTTCATCATGATATGAGCCATTCATTCAACCGAGTATAGTCTCCG CAATGTTCGCCTTCATCATGATATGAGCCATTCATTCAACCGAGTATAGTCTCCG

Intron $2 \quad$ AGTCTCCG GTCTCCG

TAATGTTCTCCCCCATGA-- -AATGAACATTCGTTTAACGGAGGATAGTGTCCG TAATGTTCTCCCCCATGA - - AATGAACATTCGTTTAACGGAGGATAGTCTCCG $\begin{array}{ll}\text { Intron } 2 & \text { GTCTCCG } \\ \text { GTCTCCG }\end{array}$

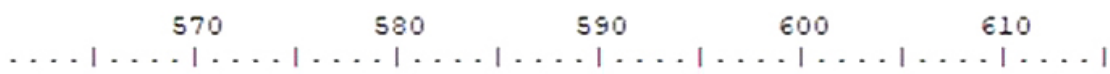
TGCCT CAGAT GTT GAAGGCCAAGGAT CAAT CGGT CGT CGGGCTTACAAAGGGTAT TGCCTCAGATGTTGAAGGCCAAGGATCAATCGGTCGTCGGGCTTACAAAGGGTAT TGCCTCAGATGTTGAAGGCCAAGGATCAATCGGTCGTCGGGCTTACAAAGGGTAT TGCCTCAGATGTTGAAGGCCAAGGATCAATCGGTCGTCGGGCTTACAAAGGGTAT TGCCTCAAATGTTGAAGGCCAAGGACCAATCGGTCGTTGGGCTGACTAAGGGTAT TGCCTCAAATGTTGAAGGCCAAGGACCAATCGGTCGTTGGGCTGACTAAGGGTAT TGCCTCAAATGTTGAAGGCCAAGGACCAATCGGTCGTTGGGCTGACTAAGGGTAT TGCCTCAAATGTTGAAGGCCAAGGACCAATCGGTCGTTGGGCTGACTAAGGGTAT

$640 \quad 650 \quad 660 \quad 670 \quad 680$ $\ldots|\ldots| \ldots|\ldots| \ldots|\ldots| \ldots|\ldots| \ldots|\ldots| \ldots|\ldots| \ldots|\ldots| \ldots|\ldots|$ GCAAAACAAGGTAGACTACATAAAGGGTACCGGTTCTTTCGTTTCCCCAACGCGT GCAAAACAAGGTAGACTACATAAAGGGTACCGGTTCTTTCGTTTCCCCAACGCGT GCAAAACAAGGTAGACTACATAAAGGGTACCGGTTCTTTCGTTTCCCCAACGCGT GCAAAACAAGGTAGACTACATAAAGGGTACCGGTTCTTTCGTTTCCCCAACGCGT GCAAAACAAGGTAGACTACATCAAGGGGAGCGGTTCTTTTGTTTCTCCAACACGC GCAAAACAAGGTAGACTACATCAAGGGGAGCGGTTCTTTTGTTTCTCCAACACGC GCAAAACAAGGTAGACTACATCAAGGGGAGCGGTTCTTTTGTTTCTCCAACACGC GCAAAACAAGGTAGACTACATCAAGGGGAGCGGTTCTTTTGTTTCTCCAACACGC

(b) 
X. pruinatus-F.s.-DNA-P1 X.p.-P.a.-DNA-P2

X.p. -F.s.-CDNA-P1

X.p.-P.a.-CDNA-P2

X.badius-F.s.-DNA-P1

$\mathrm{X} \cdot \mathrm{b} \cdot-\mathrm{P} \cdot \mathrm{a} \cdot-\mathrm{DNA}-\mathrm{P} 2$

X.b.-F.s.-CDNA-P1

X.b. $-\mathrm{P} \cdot \mathrm{a},-\mathrm{CDNA}-\mathrm{P} 2$

X. pruinatus-F.s.-DNA-P1

X.p.-P.a.-DNA-P2

X.p. -F.s.-CDNA-P1

X.p. -P.a.-CDNA-P2

X.badius-F.s.-DNA-P1

$\mathrm{X} \cdot \mathrm{b},-\mathrm{P} \cdot \mathrm{a} \cdot-\mathrm{DNA}-\mathrm{P} 2$

X.b. - F.s. - CDNA-P1

X.b.-P.a.-CDNA-P2

X. pruinatus-F.s.-DNA-P1

$\mathrm{X} \cdot \mathrm{p} \cdot-\mathrm{P} \cdot \mathrm{a} \cdot-\mathrm{DNA}-\mathrm{P} 2$

X.p. -F.s.-CDNA-P1

X.p.-P.a.-CDNA-P2

X.badius-F.s.-DNA-P1

X.b.-P.a.-DNA-P2

X.b. -F.s.-CDNA-P1

X.b.-P.a.-CDNA-P2

X. pruinatus-F.s.-DNA-P1

X.p.-P.a.-DNA-P2

X.p. -F.s.-CDNA-P1

$\mathrm{X} \cdot \mathrm{p},-\mathrm{P} \cdot \mathrm{a},-\mathrm{CDNA}-\mathrm{P} 2$

X.badius-F.s.-DNA-P1

X.b.-P.a.-DNA-P2

X.b.-F.s.-CDNA-P1

X.b.-P.a.-CDNA-P2

X. pruinatus-F.s.-DNA-P1

$\mathrm{X} \cdot \mathrm{p} \cdot-\mathrm{P} \cdot \mathrm{a} \cdot-\mathrm{DNA}-\mathrm{P} 2$

X.p. -F.s.-CDNA-P1

X.p.-P.a.-CDNA-P2

X.badius-F.s.-DNA-P1

$\mathrm{X} \cdot \mathrm{b} \cdot-\mathrm{P} \cdot \mathrm{a} \cdot-\mathrm{DNA}-\mathrm{P} 2$

X.b. - F.s.-CDNA-P1

X.b.-P.a.-CDNA-P2
710

720

730

740

750

$\ldots|\ldots| \ldots|\ldots| \ldots|\ldots| \ldots|\ldots| \ldots|\ldots| \ldots|\ldots|$ CTCGAGGGTGGCGAGACGGAAATCGAGGCAAAGAACGTCATCATTGCTACCGGCT CTCGAGGGTGGCGAGACGGAAATCGAGGCAAAGAACGTCATCATTGCTACCGGCT CTCGAGGGTGGCGAGACGGAAATCGAGGCAAAGAACGTCATCATTGCTACCGGCT CTCGAGGGTGGCGAGACGGAAATCGAGGCAAAGAACGTCATCATTGCTACCGGCT CTCGAGGGTGGCGAGACGGAAATTGAGGCAAAGAACGTCATCATTGCTACCGGCT CTCGAGGGTGGCGAGACGGAAATTGAGGCAAAGAACGTCATCATTGCTACCGGCT CTCAAGGGTGGCGAGACGGAAATTGAGGCAAAGAACGTCATCATTGCTACCGGCT CTCGAGGGTGGCGAGACGGAAATTGAGGCAAAGAACGTCATCATTGCTACCGGCT

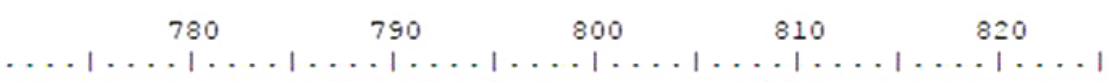
TTCCCAGGGGGCGCCATTCAAA-TAGACGAGAAGCAAATCGTCAGCTCGACAGGT TTCCCAGGGGGCGCCATTCAAA - TAGACGAGAAGCAAATCGTCAGCTCGACAGGT TTCCCAGGGGGCGCCATTCAAA - TAGACGAGAAGCAAATCGTCAGCTCGACAGGT TTCCCAGGGGGCGCCATTCAAA - TAGACGAGAAGCAAATCGTCAGCTCGACAGGT TTCCCAGGGGGCGCCATTCAAATTAGACGAGAAGCAAATCGTCAGCTCGACAGGC TTCCCAGGGGGCGCCATTCAAATTAGACGAGAAGCAAATCGTCAGCTCGACAGGC TTCCCAGGGGGCGCCATTCAAATTAGACGAGAAGCAAATCGTCAGCTCGACAGGC TTCCCAGGGGGCGCCATTCAAATTAGACGAGAAGCAAATCGTCAGCTCGACAGGC

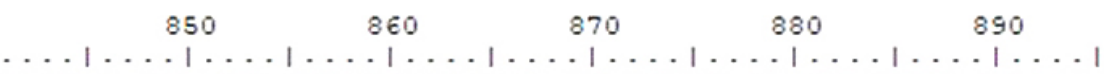
GAGGTACGAGATAAGATGGTGGT CATCGGCGGTGGTATCATTGGTTTGGAGATGG GAGGTACCAGATAAGATGGTGGTCATCGGCGGTGGTATCATTGGTTTGGAGATGG GAGGTACCAGATAAGATGGTGGTCATCGGCGGTGGTATCATTGGTTTGGAGATGG GAGGTACCAGATAAGATGGTGGTCATCGGCGGTGGTATCATTGGTTTGGAGATGG GAGGTGCCAAATAAGATGGTCGTCATCGGCGGTGGTATCATTGGTTTGGAGATGG GAGGTGCCAAATAAGATGGTCGTCATCGGCGGTGGTATCATTGGTTTGGAGATGG GAGGTGCCAAATAAGATGGTCGTCATCGGCGGTGGTATCATTGGTTTGGAGATGG GAGGTGCCAAATAAGATGGTCGTCATCGGCGGTGGTATCATTGGTTTGGAGATGG

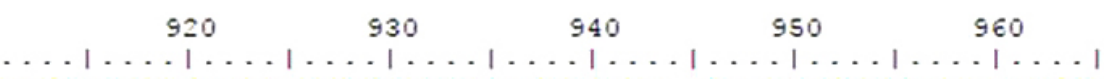
GACTTGGCGCTGAGGTCACTGTTGTTGAGTTCC-TTGGTGGCATCGGCGGTGCTG GACTTGGCGCTGAGGTCACTGTTGTTGAGTTCC-TTGGTGGCATCGGCGGTGCTG GACTTGGCGCTGAGGTCACTGTTGTTGAGTTCC-TTGGTGGCATCGGCGGTGCTG GACTTGGCGCTGAGGTCACTGTTGTTGAGTTCC-TTGGTGGCATCGGCGGTGCTG GACTTGGCGCTGAGGTGACTGTGGTCGAGTTCC-TTGGTGGCATCGGCGGTGTTG GACTTGGCGCTGAGGTGACTGTGGTCGAGTTCC-TTGGTGGCATCGGCGGTGTTG GACTTGGCGCTGAGGTGACTGTGGTCGAGTTCCTTTGGTGGCATCGGCGGTGTTG GACTTGGCGCTGAGGTGACTGTGGTCGAGTTCC-TTGGTGGCATCGGCGGTGTTG

$990 \quad 1000 \quad 1010 \quad 1020 \quad 1030$

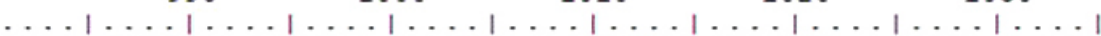
TCGCGTGAG - TGTAGCACGCACACCGTGGTCCGCGCTTGCTCTGATGGGTCTTTG TCGCGTGAG - TGTAGCACGCACACCGTGGTCCGCGCTTGCTCTGATGGGTCTTTG TCGC

TCGC

Intron 3

TTGCGTGAGTTGTAGTACTTCTCCCGCGGTCCACACTGG-TCTCACGAGTCTTTA TTGCGTGAG-TGTAGTACTTCTCCCGCGGTCCACACTGG-TCTCACGAGTCTTTA TTGC

TTGC

Intron 3

(c) 
X. pruinatus-F.s.-DNA-P1 X.p.-P.a.-DNA-P2

X.p.-F.s.-CDNA-P1

X.p.-P.a.-CDNA-P2

X.badius-F.s.-DNA-P1

X.b.-P.a.-DNA-P2

X.b.-F.s.-CDNA-P1

X.b.-P.a.-CDNA-P2

X. pruinatus-F.s.-DNA-P1

X.p.-P.a.-DNA-P2

X.p. -F.s.-CDNA-P1

X.p.-P.a.-CDNA-P2

X.badius-F.s.-DNA-P1

X.b.-P.a.-DNA-P2

X.b. - F.s. - CDNA-P1

X.b.-P.a.-CDNA-P2

X. pruinatus-F.s.-DNA-P1

X.p.-P.a.-DNA-P2

X.p. -F.s.-CDNA-P1

$\mathrm{X} \cdot \mathrm{p} \cdot-\mathrm{P} \cdot \mathrm{a} \cdot-\mathrm{CDNA}-\mathrm{P} 2$

X.badius-F.s.-DNA-P1

X.b.-P.a.-DNA-P2

X.b.-F.s.-CDNA-P1

X.b.-P.a.-CDNA-P2

X. pruinatus-F.s.-DNA-P1

X.p. - P.a.-DNA-P2

X.p. -F.s.-CDNA-P1

X.p.-P.a.-CDNA-P2

X.badius-F.s.-DNA-P1

X.b.-P.a.-DNA-P2

X.b. -F.s.-CDNA-P1

X.b.-P.a.-CDNA-P2

X. pruinatus-F.s.-DNA-P1

X.p.-P.a.-DNA-P2

X.p. -F.s.-CDNA-P1

X.p.-P.a.-CDNA-P2

X.badius-F.s.-DNA-P1

X.b.-P.a.-DNA-P2

X.b. -F.s.-CDNA-P1

X.b.-P.a.-CDNA-P2
$1060 \quad 1070 \quad 1080 \quad 1090 \quad 1100$

$\ldots|\ldots| \ldots|\ldots| \ldots|\ldots| \ldots|\ldots| \ldots|\ldots| \ldots|\ldots| \ldots \mid$

GAAGATTCTGGCGAAGCAAGGCATCAAGTTCAAGCTGGGCACCAAGGTCTTGTCC GAAGATTCTGGCGAAGCAAGGCATCAAGTTCAAGCTGGGCACCAAGGTCTTGTCC GAAGATTCTGGCGAAGCAAGGCATCAAGTTCAAGCTGGGCACCAAGGTCTTGTCC GAAGATTCTGGCGAAGCAAGGCATCAAGTTCAAGCTGGGCACCAAGGTCTTGTCC GAAGATCTTGGCGAAACAAGGCCTCAAGTTCAAGCTGAACACGAAAGTCATGTCC GAAGATCTTGGCGAAACAAGGCCTCAAGTTCAAGCTGAACACGAAAGTCATGTCC GAAGATCTTGGCGAAACAAGGCCTCAAGTTCAAGCTGAACACGAAAGTCATGTCC GAAGATCTTGGCGAAACAAGGCCTCAAGTTCAAGCTGAACACGAAAGTCATGTCC

$1130 \quad 1140 \quad 1150 \quad 1160 \quad 1170$ $\ldots|\ldots| \ldots|\ldots| \ldots|\ldots| \ldots|\ldots| \ldots|\ldots| \ldots|\ldots|$ GGAAAAGTCCTCGTTAAGACGCGATCTGCCAAGGGTGACAAGGAAGAGACCGTAA GGAAAAGTCCTCGTTAAGACGCGATCTGCCAAGGGTGACAAGGAAGAGACCGTAA GGAAAAGTCCTCGTTAAGACGCGATCTGCCAAGGGTGACAAGGAAGAGACC GGAAAAGTCCTCGTTAAGACGCGATCTGCCAAGGGTGACAAGGAAGAGACC GGAAAAGTCCTCGT CAAGACGCAATCTCCCAAGGGCGACAAGGAGGAGACTGTAA GGAAAAGTCCTCGTCAAGACGCAATCTCCCAAGGGCGACAAGGAGGAGACTGTAA GGAAAAGTCCTCGTCAAGACGCAATCTCCCAAGGGCGACAAGGAGGAGACT GGAAAAGTCCTCGTCAAGACGCAATCTGCCAAGGGCGACAAGGAGGAGACT

$$
1200 \quad 1210 \quad 1220 \quad 1230 \quad 1240
$$

$\ldots|\ldots| \ldots|\ldots| \ldots|\ldots| \ldots|\ldots| \ldots|\ldots| \ldots|\ldots| \ldots|\ldots| \ldots \mid$ CTTGGGTA GAGAGTAACCTTGTCTATCGTAGCTCGAAGCCGACGTCGTTTTG CTTGGGTA - GAGAGTAACCTTGTCTATCGTAGCTCGAAGCCGACGTCGTTTTG Intron 4 CTCGAAGCCGACGTCGTTTTG CTCGAAGCCGACGTCGTTTTG

TCTCGTGTTCGAGAAGTAACCTGTACATTTTTAGATCGAGGCAGACGTTGTTTTG CCTCGTGTTC-AGAAGTAACCTGTACATTTTTAGATCGAGGCAGACGTTGTTTTG Intron 4 ATCGAGGCAGACGTTGTTTTG ATCGAGGCAGACGTTGTTTTG

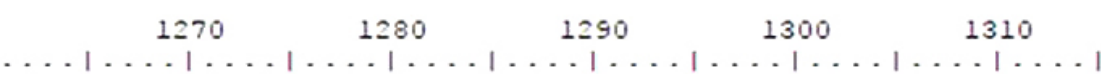
CGTCCATA-TACGGAGGGCCTTAACCTTGAGGCTCTT--GGTGTCGAGAAAGAC CGTCCATA-TACGGAGGGCCTTAACCTTGAGGCTCTT---GGTGTCGAGAAAGAC CGTCCATA-TACGGAGGGCCTTAACCTTGAGGCTCTT-- GGTGTCGAGAAAGAC CGTCCATA-TACGGAGGGCCTTAACCTTGAGGCTCTT-- GGTGTCGAGAAAGAC CGTCCATA CACGGAGGGTCTCAACCTCGAAGCTTTC--GGTGTCGAGAAAGAC CGTCCATA- CACGGAAGGTCTCAACCTCGAAGCTTTC---GTTGTCGAGAAAGAC CGTCCATA CACGGAGGGTCTCAACCTCGAAGCTTTC--GGTGTCGAGAAAGAC CGTCCATA CACGGAGGGTCTCAACCTCGAAGCTTTTCGGGTTGTCGAGAAAGAC

$$
1340 \quad 1350 \quad 1360 \quad 1370 \quad 1380
$$
$\ldots|\ldots| \ldots|\ldots| \ldots|\ldots| \ldots|\ldots| \ldots|\ldots| \ldots|\ldots| \ldots|\ldots| \ldots \mid$ ATCATCGATGACCAGTTCAGTACCTCGGTCAAGAACATCAAGTGCATCGGTGACG ATCATCGATGACCAGTTCAGTACCTCGGTCAAGAACATCAAGTGCATCGGTGACG ATCATCGATGACCAGTTCAGTACCTCGGTCAAGAACATCAAGTGCATCGGTGACG ATCATCGATGACCAGTTCAGTACCTCGGTCAAGAACATCAAGTGCATCGGTGACG ATCATCGATGACCAGTTCAACACTTCAGTCAAGAACATCAAGTGTATCGGTGATG ATCATCGATGACCAGTTCAACACTTCAGTCAAGAACATCAAGTGTATCGGTGATG ATCATCGATGACCAGTTCAACACTTCAGTCAAGAACATCAAGTGTATCGGTGATG ATCATCGATGACCAGTTCAACACTTCAGTCAAGAACATCAAGTGTATCGGTGATG

(d) 
X. pruinatus-F.s.-DNA-P1 X.p.-P.a.-DNA-P2

X.p.-F.s.-CDNA-P1

X.p.-P.a.-CDNA-P2

X.badius-F.s. -DNA-P1

X.b.-P.a.-DNA-P2

X.b.-F.s.-CDNA-P1

X.b. - P.a.-CDNA-P2

X. pruinatus-F.s.-DNA-P1

$\mathrm{X} \cdot \mathrm{p} \cdot-\mathrm{P} \cdot \mathrm{a},-\mathrm{DNA}-\mathrm{P} 2$

X.p.-F.s.-CDNA-P1

X.p. - P.a.-cDNA-P2

X.badius-F.s.-DNA-P1

X.b. -P.a.-DNA-P2

X.b. -F.s. -CDNA-P1

X.b.-P.a.-CDNA-P2

X. pruinatus-F.s.-DNA-P1

X.p.-P.a.-DNA-P2

X.p. -F.s.-cDNA-P1

$\mathrm{X} \cdot \mathrm{p} \cdot-\mathrm{P} \cdot \mathrm{a} \cdot-\mathrm{CDNA}-\mathrm{P} 2$

X.badius-F.s.-DNA-P1

X.b. -P.a.-DNA-P2

X.b.-F.s. -CDNA-P1

X.b.-P.a.-CDNA-P2

X. pruinatus-F.s.-DNA-P1

X.p.-P.a.-DNA-P2

X.p. - F.s. - CDNA-P1

$\mathrm{X} \cdot \mathrm{p},-\mathrm{P} \cdot \mathrm{a},-\mathrm{CDNA}-\mathrm{P} 2$

X.badius-F.s.-DNA-P1

X.b.-P.a.-DNA-P2

X.b. -F.s. - CDNA-P1

X.b.-P.a.-CDNA-P2

X. pruinatus-F.s.-DNA-P1

$\mathrm{X} \cdot \mathrm{p} \cdot-\mathrm{P} \cdot \mathrm{a} \cdot-\mathrm{DNA}-\mathrm{P} 2$

X.p.-F.s.-CDNA-P1

X.p. - P.a.-cDNA-P2

X.badius-F.s.-DNA-P1

X.b. -P.a.-DNA-P2

X.b.-F.s.-CDNA-P1

X.b. - P.a.-CDNA-P2
$1410 \quad 1420 \quad 1430 \quad 1440 \quad 1450$

$\ldots|\ldots| \ldots|\ldots| \ldots|\ldots| \ldots|\ldots| \ldots|\ldots| \ldots|\ldots| \ldots \mid$ TGCTCGCACACAAGGCTGAGGAGGAAGGTATCGCTGCTGTCGAATACCTCAAATC TGCTCGCACACAAGGCTGAGGAGGAAGGTATCGCTGCTGTCGAATACCTCAAATC TGCTCGCACACAAGGCTGAGGAGGAAGGTATCGCTGCTGTCGAATACCTCAAATC TGCTCGCACACAAGGCTGAGGAGGAAGGTATCGCTGCTGTCGAATACCTCAAATC TGCTCGCGCACAAGGCGGAGGAGGAGGGTATCGCTGCTGTTGAATATATCAAGTC TGCTCGCGCACAAGGCGGAGGAGGAGGGTATCGCTGCTGTTGATTATATCAAGTC TGCTCGCGCACAAGGCGGAGGAGGAGGGTATCGCTGCTGTTGAATATATCAAGTC TGCTCGCGCACAAGGCGGAGGAGGAGGGTATCGCTGCTGTTGAATATATCAAGTC

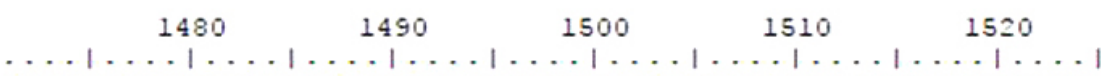
CAACTACAACGGCATTCCTTCTGTCGTCTACACCCACCCCGAGGTTGCCTGGGTG CAACTACAACGGCATTCCTTCTGTCGTCTACACCCACCCCGAGGTTGCCTGGGTG CAACTACAACGGCATTCCTTCTGTCGTCTACACCCACCCCGAGGTTGCCTGGGTG CAACTACAACGGCATTCCTTCTGTCGTCTACACCCACCCCGAGGTTGCCTGGGTG CAACTACAACGGCATTCCTTCTGTCGTCTACACCCACCCCGAGGTTGCATGGGTA CAACT ACAACGGCATTCCTTCTGTCGTCTACACCCACCCCGAGGTTGCATGGGTA CAACTACAACGGCATTCCTTCTGTCGTCTACACCCACGCCGAGGTTGCATGGGTA CAACTACAACGGCATTCCTTCTGTCGTCTACACCCACCCCGAGGTTGCATGGGTA

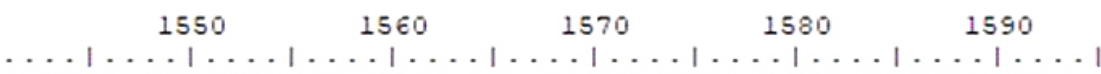
GATCTCAAGGCCACCGGTGTCCAATACAATATTGGAAAATTCCCCTTTGCTGCCA GATCTCAAGGCCACCGGTGTCCAATACAATATTGGAAAATTCCCCTTTGCTGCCA GATCTCAAGGCCACCGGTGTCCAATACAATATTGGAAAATTCCCCTTTGCTGCCA GATCTCAAGGCCACCGGTGTCCAATACAATATTGGAAAATTCCCCTTTGCTGCCA GACCTCAAGGCTGCCGGTGTTCAGTACAACGTTGGAAAATTCCCGTTCGCTGCTA GACCTCAAGGCTGCCGGTGTTCAGTACAACGTTGGAAAATTCCCGTTCGCTGCTA GACCTCAAGGCTGCCGGTCTTCAGTACAACGTTGGAAAATTCCCGTTCGCTGCTA GACCTCAAGGCTGCCGGTGTTCAGTACAACGTTGGAAAATTCCCGTTCGCTGCTA

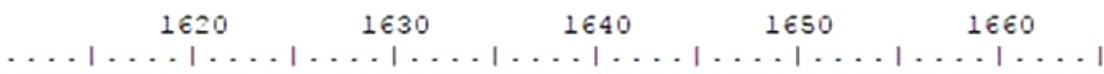
CGAATCTTGACAGCGAGGGCTTTGTCAAGTTCCTTTCTGAGAAGGAGACCGACAG CGAATCTTGACAGCGAGGGCTTTGTCAAGTTCCTTTCTGAGAAGGAGACCGACAG CGAATCTTGACAGCGAGGGCTTTGTCAAGTTCCTTTCTGAGAAGGAGACCGACAG CGAATCTTGACAGCGAGGGCTTTGTCAAGTTCCTTTCTGAGAAGGAGACCGACAG CAAACCTTGACAGCGAGGGCTTTGTCAAATTCCTTTCTGAGAAGGAGACGGACAG CAAACCTTGACAGCGAGGGCTTTGTCAAATTCCTTTCTGAGAAGGAGACGGACAG CAAACCTTGACAGCGAGGGCTTTGTCAAATTCCTTTCTGAGAAGGAGACGGACAG CAAACCTTGACAGCGAGGGCTTTGTCAAATTCCTTTCTGAGAAGGAGACGGACAG
1690
1700
1710
1720
1730

$\ldots|\ldots| \ldots|\ldots| \ldots|\ldots| \ldots|\ldots| \ldots|\ldots| \ldots|\ldots|$ CATTATTGGTGAGTTTTCCTTGTCATGTTTTCACGGAGAAGAGTATTTAATCGGA CATTATTGGTGAGTTTTCCTTGTCATGTTTTCACGGAGAAGAGTATTTAATCGGA CATTATTGGT

CATTATTGGT

Intron 5

CATCATCGGTGAGTTTTCCTCGTCATGTTTTCATCAAGACGAGTATTCAATCGGG CATCATCGGTGAGTTTTCCTCGTCATGTTTTCATCAAGACGAGTATTCAATCGGG CATCATCGGT CATCATCGGT

(e) 


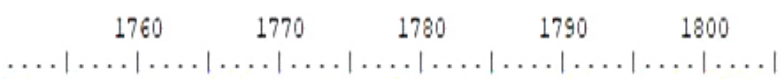

X. pruinatus-P.s.-DNA-P1 CTGGTGAAATGA-TCTCGGAAGCCGTCCTTGCTTTGGAGTACGGTGCAAGCTCGG $X . p,-P$, a. - DNA-P2 CTGGTGAAATGA-TCTCGGAAGCCGTCCTTGCTTTGGAGTACGGTGCAAGCTCGG CTGGTGAAATGA-TCTCGGAAGCCGTCCTTGCTTTGGAGTAC

X.p. -F.s. - CDNA-P1 $X . p,-P, a,-$ CDNA-P2 $X$, badius-P.s. -DNA-P1 CCGGTGAGATGA-TCTCGGAGGCGTTCTTGCTCTAGAGTATGGTGCAAGTCGG $X, b,-P, a,-D N A-P 2$ $X . b .-$ F.s. - CDNA-P1 $X, b,-P, a,-C D N A-P 2$ CCGGTGAGATGA-TCTCGGAGGCGGTTCTTGCTCTAGAGTATGGTGCAAGCTCGG C

$\begin{array}{lllll}1830 & 1840 & 1850 & 1860 & 1870\end{array}$ $\ldots+\ldots|\ldots| \ldots . \ldots|\ldots| \ldots|\ldots| \ldots|\ldots| \ldots|\ldots| \ldots \mid$ X. pruinatus-F.s.-DNA-P1 CAACTCACGCTCACGTATGTTTCTGTTCGTTCGTTGCATGCGATACGTTGACGT X.p. -P.a. -DNA-P2 CAACTCACGCTCACGTATGTTTCTGTTTCGTTCGTTGCATGCGATACGTTGACGT X.p. -F.s. -CDNA-P1 X.p. -P. a. - CDNA-P2 $X$. badius-F.s. -DNA-P1 $X . b .-P$. a. $-D N A-P 2$ X.b. - F.s. - CDNA-P1 X.b. -P.a. -cDNA-P2

\section{CAACACACGCTCACGTACGCTGTGTTCGTCGTATCT}

CAACACACGCTCACGTGTTCGTCGTATCAGTGTGAGA

1900

$1910 \quad 1920$

1930 $\ldots+\ldots|\ldots| \ldots|\ldots| \ldots|\ldots| \ldots|\ldots| \ldots$

X. pruinatus-F.s.-DNA-P1 X.p.-P.a. -DNA-P2 CCACACTCAGCGAGGCATTCAAGGAGGCTGCCATGTCGGCA

$X . p,-$ F.s. - CDNA-P1

$X . p .-P . a,-c D N A-P 2$

$X$. badius $-P$.s. -DNA-P1

X.b. -P. a. -DNA-P2

X.b. - F.s. - CDNA-P1

$X . b .-P . a,-C D N A-P 2$

(f)

Figure A1. Comparison of the DNA and cDNA sequence of the enzyme NADH diaphorase in the two ectomycorrhiza fungi Xerocomus badius $(\mathrm{Xb})$ and Xerocomus pruinatus $(\mathrm{Xp})$ in symbiosis with beech (Fagus sylvatica, Fs) and spruce (Picea abies, Pa). 